\title{
Control of Firing Mode of Corticotectal and Corticopontine Layer V Burst-generating Neurons by Norepinephrine, Acetylcholine, and 1S,3R-ACPD
}

\author{
Zhong Wang' and David A. McCormick ${ }^{2}$ \\ 'Department of Cellular and Molecular Physiology, 2Section of Neurobiology, Yale University School of Medicine, New \\ Haven, Connecticut 06510
}

The ionic mechanisms by which the firing mode of layer $\mathbf{V}$ burst-generating neurons is modulated by noradrenergic, cholinergic, and glutamate metabotropic receptors were investigated with intracellular and extracellular recordings obtained in slices of guinea pig sensorimotor and primary visual cortices maintained in vitro. Extracellular and intracellular recordings revealed that a subset of layer $\mathbf{V}$ cells spontaneously generated bursts of three to six action potentials with an interburst frequency of $0.2-4 \mathrm{~Hz}$. Depolarization of these cells with the intracellular injection of current inhibited burst firing and switched the cells to the tonic, single-spike mode of action potential generation. Intracellular recording from retrogradely labeled layer $V$ pyramidal cells that project to either the superior colliculus or pontine nuclei revealed that a substantial portion of these are burst-generating cells. Application of norepinephrine (NE), the glutamate metabotropic receptor agonist 1S,3R-aminocyclopentane-1,3-dicarboxylic acid (ACPD), or ACh to layer $\mathrm{V}$ burst-generating cells resulted in depolarization and a subsequent shift in firing pattern from spontaneously bursting to single-spike activity. Pharmacological analysis of these responses indicated that they are mediated by the $\alpha_{1}$-adrenoceptor for NE and the muscarinic subtype for ACh. Thus, the NE response was mimicked by the $\alpha$-agonist phenylephrine but not by the $\beta$-agonist isoprenaline, and was completely blocked by the $\alpha_{1}$-antagonist prazosin but not by the $\alpha_{2}$-antagonist yohimbine or the $\beta$-antagonist propranolol. Finally, the ACh effect could be mimicked by the muscarinic agonist acetyl- $\beta$-methylcholine (MCh) and was blocked by the muscarinic antagonist scopolamine.

Intracellular recordings revealed that the NE-, MCh-, and ACPD-induced responses in bursting neurons are due to the direct activation of receptors on these cells, since block of synaptic transmission with local application of TTX or bath application of low $\left[\mathrm{Ca}^{2+}\right]_{0}$ and raised $\left[\mathrm{Mg}^{2+}\right]_{0}$ did not block the postsynaptic responses. Voltage-clamp analysis of the currents involved in the depolarizing responses of bursting cells revealed that activation of $\alpha_{1}$-adrenergic, muscarinic, or glutamate metabotropic receptors resulted in a decrease

\footnotetext{
Received Sept. 14, 1992; revised Nov. 4, 1992; accepted Nov. 24, 1992.

We thank Thierry Bal and Marcus von Krosigk for comments on the manuscript and help with the anatomical techniques. This work was supported by the NIH, Klingenstein Fund, and the Sloan Foundation.

Correspondence should be addressed to David A. McCormick at the above address.

Copyright (C) 1993 Society for Neuroscience $0270-6474 / 93 / 132199-18 \$ 05.00 / 0$
}

in a potassium conductance that consisted of both a voltageindependent component and a voltage- and $\mathrm{Ca}^{2+}$-sensitive component. These results suggest that increased activity in noradrenergic, cholinergic, and glutamatergic pathways may control the firing mode of layer $\mathbf{V}$ corticotectal and corticopontine pyramidal cells by determining the resting membrane potential through modulation of both voltage-dependent and voltage-independent $K^{+}$conductances. This modulatory control of neuronal firing mode in layer $V$ pyramidal cells may have important implications in the ascending and local control of state-dependent changes in cortical activity and the interactions between cortical and subcortical structures.

[Key words: oscillation, bursting, arousal, sensorimotor cortex, visual cortex]

The excitability and pattern of activity generated by neurons in the sensorimotor and primary visual cortical areas depend upon not only the pattern of sensory receptive field stimulation, but also the state of the animal. During periods of electroencephalogram synchronization, such as during slow-wave sleep or drowsiness, cortical neuronal activity is characterized by a decrease in responsiveness to sensory inputs and the appearance of slow oscillations in both membrane potential and synaptic inputs (Evarts, 1964; Creutzfeldt et al., 1966; Livingstone and Hubel, 1981; see Steriade, 1991). Although these changes in neuronal activity in the sensorimotor and primary visual cortical regions occur in part through alterations in thalamic input, there is substantial evidence that modulatory neurotransmitter systems such as the noradrenergic cells of the locus coeruleus (LC) and the cholinergic cells of the basal forebrain may exercise an important and direct control of cortical neuronal activity (reviewed in Foote and Morrison, 1987; McCormick, 1992). For example, lesions of the basal forebrain cholinergic nuclei or pharmacological block of muscarinic receptors results in the appearance of large, slow (delta) waves throughout the cortex (Buzsáki et al., 1988; reviewed in Vanderwolf, 1988). In contrast, lesions of the LC are generally not followed by detectable increases in slow-wave activity (Jones et al., 1977), although extracellular recordings from $\mathrm{LC}$ neurons reveal that their activity is highly correlated with behavioral arousal and attentiveness to extrapersonal events (Aston-Jones and Bloom, 1981) and chemical activation of the LC results in pronounced desynchronization of the electroencephalogram, thereby indicating a block of slow oscillatory activity in cortical and thalamocortical circuits (Berridge and Foote, 1991). Iontophoretic 
application of norepinephrine (NE) to neocortical neurons in vivo results in both excitation and inhibition, with excitatory responses associated with the activation of $\alpha$-adrenoceptors and being more prevalent in deeper layer cells, while inhibitory responses are typically associated with $\beta$-adrenergic stimulation and are found throughout all layers of cortex (Bevan et al., 1977; Waterhouse et al., 1981; Armstrong-James and Fox, 1983). In contrast, application of $\mathrm{ACh}$ to cortical neurons typically results in excitation through muscarinic receptors, although inhibition, which may be mediated by excitation of local GABAergic interneurons (McCormick and Prince, 1986), has also been reported (reviewed in Krnjevic, 1975). How might cholinergic and noradrenergic excitation of infragranular cells be related to changes in the pattern of activity generated in cortical circuits? Extracellular single-unit and current source density analysis of slow-wave generation in the neocortex in vivo has implicated deep-lying (layer V) pyramidal cells in the generation of delta waves (Calvet et al., 1973; Ball et al., 1977; Rappelsberger et al., 1982). Similarly, recent in vitro intracellular and extracellular investigations of local electrical shock-evoked synchronous oscillations, or of bicuculline-induced epileptiform activity, have implicated the burst-generating pyramidal cells of layer $\mathrm{V}$ in the generation, synchronization, and dispersion of synchronized activity in the neocortex (Connors, 1984; Chagnac-Amitai and Connors, 1989; Silva et al., 1991). One possibility, therefore, is that the firing mode of layer $\mathrm{V}$ burst-generating neurons may be under the control of ascending transmitter systems that are associated with the extrathalamic control of "activation" and abolition of slow waves in the electroencephalogram.

Morphological analysis of layer $\mathrm{V}$ burst-generating pyramidal cells reveals that these cells are similar in morphology to layer $\mathrm{V}$ cells that project to the superior colliculus or pontine nuclei (Chagnac-Amitai et al., 1990; Hüberner et al., 1990; Larkman and Mason, 1990; Mason and Larkman, 1990), indicating that burst generation may be a characteristic of subcortically projecting layer $\mathrm{V}$ cells throughout ccrebral cortex. In the present study, we examine the possibility that layer $\mathrm{V}$ pyramidal cells that project to the superior colliculus and pontine nuclei may include burst-generating cells, and examine in detail the pharmacological and ionic mechanisms through which ascending cholinergic and noradrenergic, and possibly glutamatergic, systems may control the firing mode of these cells.

These results have been published previously in abstract form (Wang and McCormick, 1991, 1992).

\section{Materials and Methods}

Male or female guinea pigs were deeply anesthetized with sodium pentobarbital $(35 \mathrm{mg} / \mathrm{ml}$, i.p.) and killed by decapitation. The portion of brain anterior to the cerebellum was removed and placed in cold $\left(5^{\circ} \mathrm{C}\right)$ artificial cerebrospinal fluid that was oxygenated with $95 \% \mathrm{O}_{2}, 5 \% \mathrm{CO}_{2}$ to a final $\mathrm{pH}$ of 7.4 and contained (in $\mathrm{mM}$ ) $\mathrm{NaCl}, 126 ; \mathrm{KCl}, 2.5 ; \mathrm{MgSO}_{4}$, $1.2 ; \mathrm{Na}_{2} \mathrm{HPO}_{4}, 1.25 ; \mathrm{CaCl}_{2}, 2 ; \mathrm{NaHCO}_{3}, 26 ;$ and dextrose, 10 . Sections (400-450 $\mu \mathrm{m}$ thick) were cut on a Vibratome (Lancer Corporation). Prior to formation of slices, the brain was blocked with a razor blade so as to ensure that sections were cut in the plane of the apical dendrites of deep-lying pyramidal cells (i.e., perpendicular to the pial surface) Sensorimotor or primary visual cortical slices were collected and placed in an interface-style recording chamber (Fine Science Tools) and allowed to recover for at least $1 \mathrm{hr}$ before recording. The chamber temperature was kept at $35.5 \pm 0.5^{\circ} \mathrm{C}$.

For identification of layer $\mathrm{V}$ pyramidal cells that project to either the superior colliculus or the pontine nuclei, rhodamine microbeads were injected into these subcortical sites 2-3 d prior to formation of the slices. Guinea pigs were deeply anesthetized with a mixture of ketamine (45 $\mathrm{mg} / \mathrm{kg}, \mathrm{i} . \mathrm{m}$.) and xylazine $(7.5 \mathrm{mg} / \mathrm{kg}$, i.m.) and mounted in a Kopf stereotaxic device. In initial animals, the coordinates of the superior colliculus and pontine nuclei were determined both through dye injections and through extracellular recording of visually evoked multipleunit activity. In subsequent animals, extracellular unit recordings were not performed since this resulted in the formation of tracts through which the rhodamine beads could spread. Rhodamine microbeads (Lumafluor, New City, NY) were injected in a set of four to six $0.2-0.3 \mu \mathrm{l}$ volumes in a gridlike pattern with a calibrated fine $(5-10 \mu \mathrm{m}$ tip diameter) micropipette (Drummond Scientific Company, Broomall, PA) by applying steady pressure to the back of the pipette with a $20 \mathrm{cc}$ syringe. This method resulted in significantly less damage to the overlying cortex and significantly less spread of the injection site than could be obtained with a $2 \mu$ l Hamilton syringe. During the sectioning of cortical slices that contained rhodamine bead-labeled neurons, alternate sections were taken at 100-200 $\mu \mathrm{m}$ thickness, placed in phosphatebuffered $4 \%$ paraformaldehyde and examined on a compound microscope equipped with rhodamine fluorescence. The presence, density, and location of rhodamine-labeled cortical neurons were noted and the appropriate adjacent, $400-450-\mu \mathrm{m}$-thick slices were placed in the interface recording chamber. In three animals, in addition to the injection of rhodamine microbeads, green fluorescent beads (Katz and Iarovici, 1990) were also injected into either the superior colliculus or pontine nuclei.

The primary visual cortex in the guinea pig was readily identifiable during formation of the slices and in the recording chamber as a region of occipital cortex that contains a prominent band of white matter in layer IV and a distinct layer V. The sensorimotor cortex was considered to be a region of parietal cortex approximately $3-8 \mathrm{~mm}$ lateral to the midline and overlying the anterior half of the thalamus. Examination of these regions in Nissl-stained material confirmed our visual localization of the primary visual and sensorimotor cortical regions.

Extracellular single-unit recordings were obtained with tungsten microelectrodes (Frederick Haer, <1 M 2 ) and high-pass filtered with a cutoff frequency of $200 \mathrm{~Hz}$. Neurons that showed evidence of injury from the extracellular recording electrode (e.g., change in pattern of activity with change in position of electrode) were not included for analysis. Intracellular recording was performed with microelectrodes formed from "thin-wall" micropipette glass (World Precision Instruments) on a Sutter Instruments P-80/PC micropipette puller, filled with $4 \mathrm{M}$ potassium acetate, with a final resistance ranging from $40-50 \mathrm{M} \Omega$. For intracellular Lucifer yellow dye injections, electrodes were filled with $1.0 \mathrm{~m} \mathrm{Li-acetate}$ saturated with Lucifer yellow $\mathrm{CH}$ lithium salt (Sigma). Single-electrode current and voltage clamp was performed with an Axoclamp-2A amplifier connected to an IBM AT-style computer that operated with pCLAMP software (Axon Instruments). Switching frequencies were generally $3-4 \mathrm{kHz}$, and gain was kept between 0.5 and $1.0 \mathrm{nA} / \mathrm{mV}$. During current clamp, bridge balance was monitored and properly adjusted. During voltage clamp, headstage output was monitored continuously to ensure an adequate settling time for the microelectrode. Current versus voltage $(I-V)$ plots were obtained by gradually hyperpolarizing the neurons from holding potential of $-55 \mathrm{mV}$ to about $-120 \mathrm{mV}$ over a period of $5-10 \mathrm{sec}$. This ramp duration was chosen to allow the collection of a number of different $I-V$ plots during the transmitter response. From 3 to 10 individual current traces were averaged to reduce noise.

Agonists and some antagonists were dissolved in the bath solution and applied by the pressure-pulse technique in which a brief $(10 \mathrm{msec}$, $207-345 \mathrm{kPa}, 30-50 \mathrm{psi}$ ) pulse of nitrogen was delivered to the back of a broken micropipette with tip diameter of $2-5 \mu \mathrm{m}$, resulting in a drop of 5-15 pl. Application of norepinephrine, phenylephrine, isoprenaline, and $1 S, 3 R$-aminocyclopentane-1,3-dicarboxylic acid (ACPD) to a site on the surface of the slice within $50 \mu \mathrm{m}$ of the entry point of the recording electrode was sufficient to yield responses. In contrast, application of acetylcholine or acetyl- $\beta$-methylcholine (MCh) required the lowering of the micropipette into the slice in order to obtain robust responses, as reported previously (McCormick and Prince, 1986). Blockade of drug responses with local application of antagonist was achieved by repeatedly applying the antagonist (dissolved in the bathing medium) to the region local to the recording site after obtaining a control response to the agonist. Local and bath-applied antagonists were effective for prolonged periods $(>1 \mathrm{hr}$ ) of time. All drugs were obtained from Sigma Chemical Co. (St. Louis, MO), except for ACPD, which was obtained from Tocris Neuramin (England).

Intracellular labeling of neurons was achieved after physiological characterization (presence or absence of burst discharges) and examination of responses to $\mathrm{NE}, \mathrm{ACh}$, or $\mathrm{ACPD}$ by passing $1 \mathrm{nA}$ of hyperpolarizing 
A
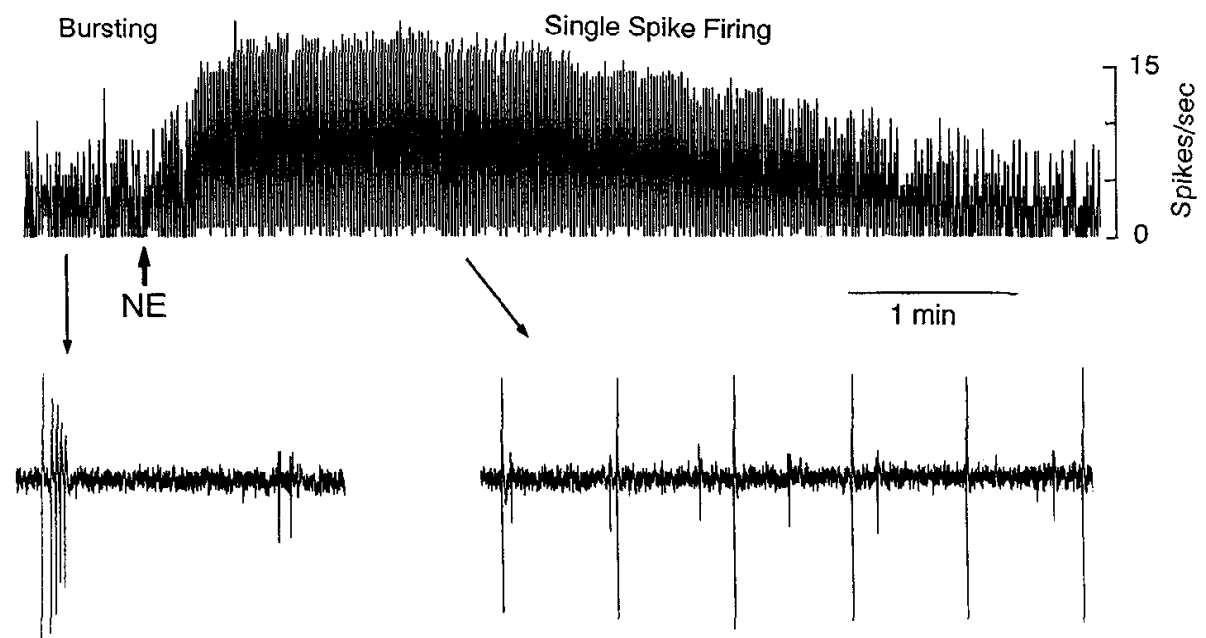

B
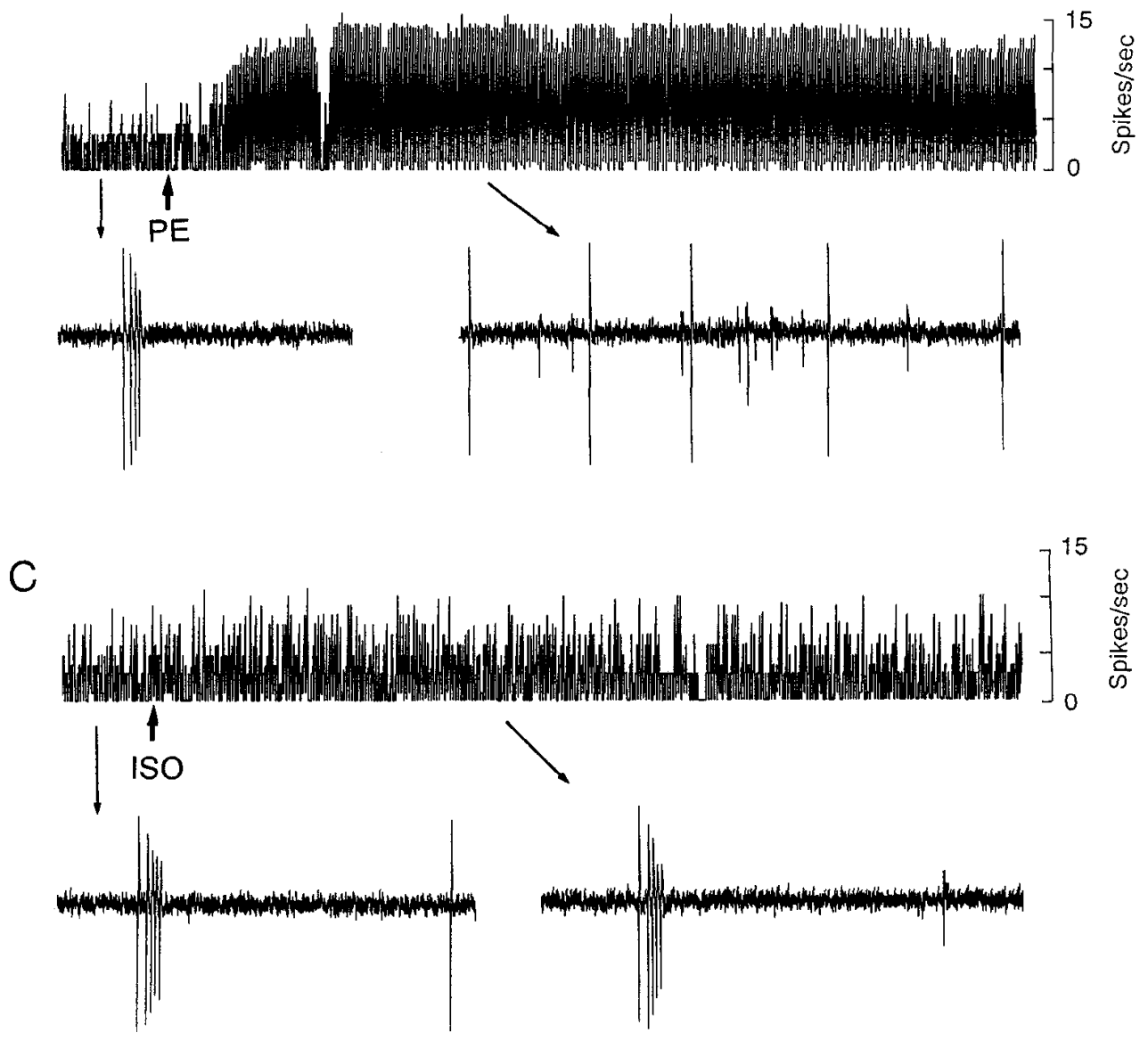

Figure 1. Pharmacological properties of excitatory response to NE. Application of NE to a spontaneously bursting layer $\mathrm{V}$ cell recorded extracellularly resulted in suppression of burst firing and an increase in single-spike activity. Examples of bursts and single-spike activity are shown for detail. $B$, Application of the $\alpha$-agonist phenylephrine has a similar effect. $C$, Application of the $\beta$-agonist isoprenaline has no discernible effect in this cell. current for a period of at least $10 \mathrm{~min}$. The electrophysiological properties of the recorded cclls were examincd within the first $10 \mathrm{~min}$ of recording in order to avoid any problems that might arise from the intracellular injection of $\mathrm{Li}^{+}$, which is known to block $\mathrm{K}^{+}$conductances (Binah et al., 1988). The main effect of intracellular injection of $\mathrm{Li}^{+}$was to prolong the duration of action potentials, and in no case did prolonged injection result in neurons initially characterized as "regular spiking" to behave as "burst-generating" cells $(n=42)$. The location and depth of the labeled cell were noted, and subsequent to the labeling of two to four cells per slice, the slice was gently removed from the recording chamber and placed in $4 \%$ phosphate-buffered paraformaldehyde overnight. Slices were sunk in $30 \%$ sucrose and resectioned on a freezing microtome at $75-100 \mu \mathrm{m}$. Sections containing Lucifer yellow-labeled cells were mounted on unsubbed slides and allowed to air dry thoroughly for clearing. Coverslips were mounted with Aquamount (Polysciences) and cells were examined and photographed with a compound microscope equipped with fluorescence for both rhodamine and Lucifer yellow. Double-labeled cells were considered to be any Lucifer yellowlabeled cell that contained at least 10 rhodamine microbeads. The morphological features of layer $\mathrm{V}$ pyramidal cells that did not exhibit pronounced morphological damage from dye injection (beaded dendrites or the appearance of large "vacuoles") were reconstructed with camera lucida drawing techniques. Approximate borders of cortical layers were examined by counterstaining with thionin. 
Layer V Burst Generating Neuron

$-64$
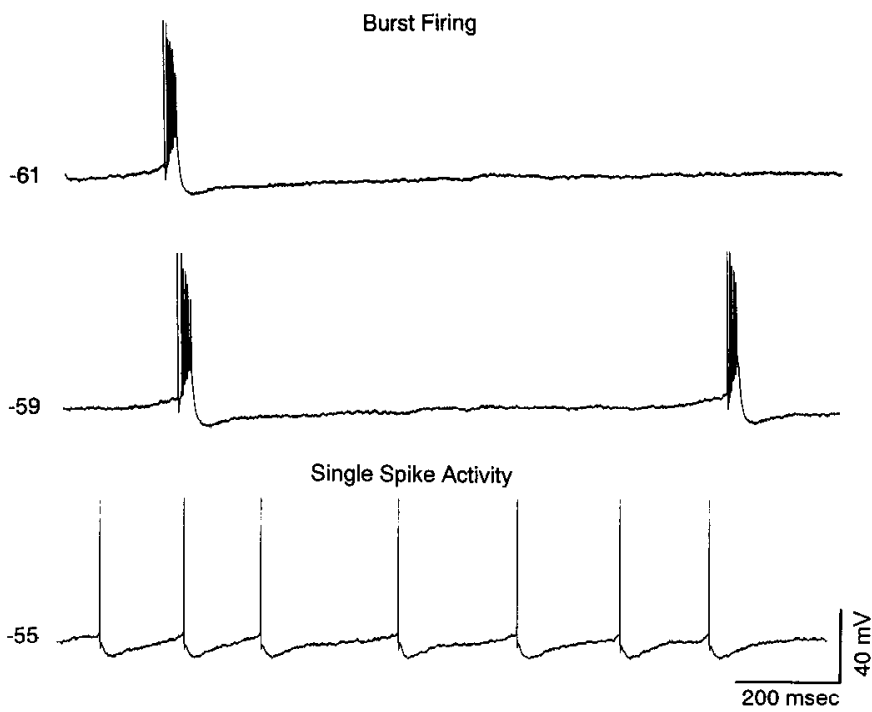

Figure 2. Pattern of activity generated by burst-generating neurons at different membrane potentials. At a membrane potential of -64 , the neuron was silent. Depolarization to $-61 \mathrm{mV}$ results in the appearance of spontaneous burst discharge. Depolarization further to $-59 \mathrm{mV}$ results in an increase in the frequency of burst firing. Further depolarization to $-55 \mathrm{mV}$ switches the firing pattern to single-spike activity.

\section{Results}

Extracellular recordings of bursting neurons

The effects of $\mathrm{NE}, \mathrm{ACh}$, and the glutamate metabotropic agonist ACPD on layer $V$ neurons were examined through extracellular and intracellular recordings. Extracellular recordings from both sensorimotor and primary visual cortex revealed a general lack of spontaneous activity by cortical neurons, as reported previously (McCormick and Prince, 1986). However, an exception to this lack of activity was the presence of spontaneously bursting neurons in layer V (Fig. $1 ; n=40$ ). These spontaneous bursts appeared in multiple-unit recordings as asynchronous events in different cells, suggesting that they may be generated through events intrinsic to each cell. The spontaneous burst firing varied in frequency of occurrence and regularity from cell to cell, with some cells generating bursts of action potentials at a regular rate of $0.2-4 \mathrm{~Hz}$ and other cells generating bursts only intermittently. It is not possible to estimate the percentage of cells generating spontaneous burst discharges, since many cells appeared to be silent and could be caused to burst with local applications of NE (see below).

The extracellularly recorded responses of layer $\mathrm{V}$ burst-generating neurons to NE (500 $\mu_{\mathrm{M}}$ in micropipette; $\left.n=25\right), \mathrm{ACh}$ ( $5 \mathrm{mM} ; n=10)$, and ACPD $(200 \mu \mathrm{M} ; n=18)$ exhibited a number of similar components, including an increase in the rate of rhythmic burst firing, followed by a switch to the single-spike mode of action potential generation (Fig. 1). The maximal frequency of rhythmic burst firing observed after the application of any of these agonists was $2-10 \mathrm{~Hz}$ and was observed just prior to the switch to the tonic firing mode (see Fig. 3). An additional response to $\mathrm{NE}$ and $\mathrm{ACh}$ that appeared in some neurons was a period of inhibition of spontaneous burst firing immediately after agonist application and prior to the increase in rhythmic burst discharge (e.g., see Fig. 3).

The pharmacological properties of the receptors mediating the responses to $\mathrm{NE}$ and $\mathrm{ACh}$ were investigated through the application of specific agonists and antagonists. Application of the $\alpha$-agonist phenylephrine (200 $\mu \mathrm{M} ; n=6)$ mimicked the response to $\mathrm{NE}$ and resulted in suppression of spontaneous burst firing and the appearance of single-spike discharge (Fig. $1 B$ ). In contrast, application of the $\beta$-agonist isoprenaline $(200 \mu \mathrm{M} ; n=$ 3) resulted in either no detectable response (Fig. 1C) or a decrease in the rate of spontaneous burst discharge (not shown). These results suggest that the excitatory effects of NE are mediatcd by $\alpha$-adrenoccptors. Indecd, local application of the spccific $\alpha_{1}$-antagonist prazosin (0.5-1 $\mu \mathrm{M}$ bath or $10 \mu \mathrm{M}$ in micropipette; $n=6$ ) resulted in a complete block of the excitatory effect of NE (not shown; see Fig. 3 below). In contrast, bath applications of the $\alpha_{2}$-antagonist yohimbine $(20 \mu \mathrm{M} ; n=3)$ or the $\beta$-antagonist propranolol $(20 \mu \mathrm{M} ; n=3)$ failed to block the excitatory effects of NE (not shown). These results indicate that the increase in rate of spontaneous burst firing and subsequent switch to single-spike activity resulting from the application of $\mathrm{NE}$ are mediated through the stimulation of $\alpha_{1}$-adrenoceptors. The pharmacological properties of the receptors mediating the inhibition of burst firing seen in the presence of prazosin (see Fig. 3D) were not investigated since this response was observed in only a minority of neurons.

The ability of $\mathrm{ACh}$ to excite layer $\mathrm{V}$ burst-generating neurons appears to be mediated through muscarinic receptors since this response was mimicked by the specific muscarinic agonist $\mathrm{MCh}$ ( $5 \mathrm{~mm}$ in micropipette; $n=25$ ) and blocked by local application of the muscarinic antagonist scopolamine $(10 \mu \mathrm{M}$ in micropipette; $n=3$ ). The pharmacological properties of the excitatory amino acid receptor mediating the response to ACPD were not investigated further.

\section{Intracellular recordings of bursting neurons}

Intracellular recordings were obtained from intrinsic bursting neurons in layer $\mathrm{V}$ of both the sensorimotor $(n=46)$ and primary visual ( $n=122)$ cortical regions. In all of these cells, intracellular injection of a depolarizing current pulse resulted in the generation of a complex of three to five action potentials, typically associated with an increase in duration and decrease in amplitude of each subsequent action potential within the burst, as we have demonstrated previously (McCormick et al., 1985). In addition to burst-generating neurons, other cells generated either a complex of two action potentials (a "doublet") as the initial response to a depolarizing current pulse, or a train of action potentials with no indication of grouping of the action potentials together even when the cells were hyperpolarized to different membrane potentials $(n=41)$. We refer here to three different physiological cell groups: "intrinsic bursting" cells are those that generate a burst of three or more action potentials at threshold (Fig. 2), "doublet-firing" cells are similar to burst-generating cells except that there are only two action potentials in the initial response (see Fig. 10 below), and "regular-spiking" cells are those that generate trains of well-spaced action potentials that do not appear together in groups at threshold (see also McCormick et al., 1985; Connors and Gutnick, 1990). Investigation of the morphological and axonal connections of intrinsic bursting and doublet-firing cells suggests that they may be members of the same subgroup of layer V cells (see below), while regularspiking cells may not (Kasper et al., 1991). 

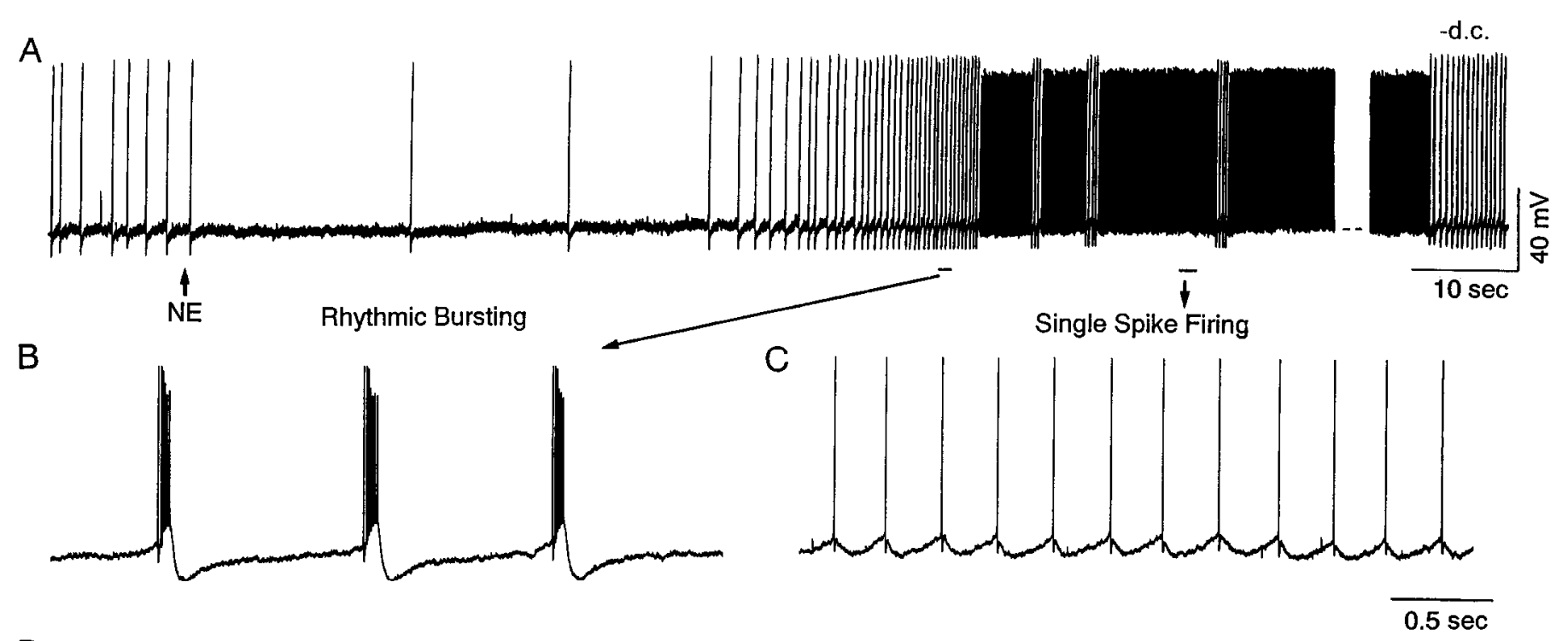

D Prazosin

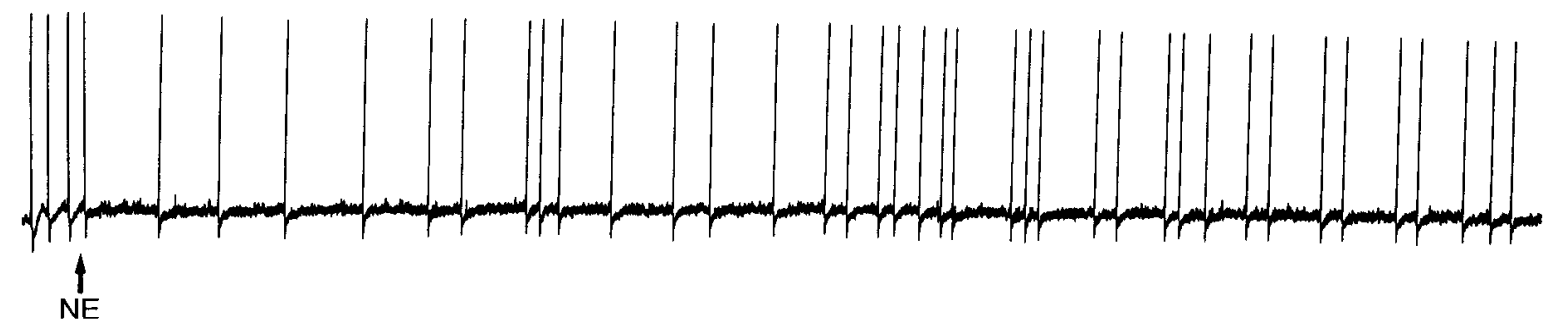

Figure 3. Response of spontaneously bursting layer $\mathrm{V}$ cell to NE. A, Application of NE results initially in a decrease in the rate of spontaneous burst generation followed by an increase in burst frequency and a subsequent switch to the single-spike mode of action potential generation. Hyperpolarization of the cell through the intracellular injection of inward current $(-d . c$.) results in a reinstatement of rhythmic burst firing. $D$, Local application of the $\alpha_{1}$-antagonist prazosin abolishes the ability of NE to depolarize the cell and change the firing mode from burst to singlespike activity. A small decrease in rate of burst firing remains, although it is less than that seen in $A$.

Of 40 intrinsic bursting neurons recorded intracellularly with $\mathrm{K}$-acetate-filled microelectrodes (i.e., not containing Li-acetate), 20 were spontaneously burst firing at resting membrane potential, or after steady depolarization with the intracellular injection of current (Fig. 3). The rate of burst firing varied from 0.2 to $10 \mathrm{~Hz}$ according to membrane potential, with depolarization increasing burst frequency (Fig. 2). During spontaneous burst firing, each burst of action potentials was followed by a pronounced afterhyperpolarization (AIIP; Fig. 2). Depolarization above a membrane potential of approximately $-57 \mathrm{mV}$ resulted in most cells in an abrupt change in firing mode to the singlespike pattern of action potential generation (Fig. 2). In many (35 of 40) cells this single-spike activity showed a marked regularity at 2-40 $\mathrm{Hz}$ with an apparent lack of spike frequency adaptation (Fig. 2, $-55 \mathrm{mV}$; see also Silva et al., 1991).

\section{Transmitter modulation of fring mode of burst-generating neurons}

In similarity to extracellular recordings, application of NE to intracellularly recorded spontaneously bursting neurons resulted in an initial decrease in burst firing in some cells $(n=4$ of 26) followed by an increase in rate of burst generation and an abrupt switch to the single-spike mode of action potential generation in most ( $n=21$ of 26 ; Fig. 3). The ability of NE to block spontancous burst firing and promote the occurrence of singlespike activity appears to result merely from the depolarization of the cell, since hyperpolarization of the membrane potential back to the pre-NE membrane potential resulted in a reinstatement of rhythmic burst firing in these cells (Fig. $3 A$, - d.c.). In confirmation of the pharmacological results obtained with extracellular recordings, local application of the $\alpha_{1}$-antagonist prazosin (10 $\mu \mathrm{M} ; n=3)$ resulted in a complete abolition of the depolarizing effects of NE, but did not block the ability of this neurotransmitter to transiently inhibit spontaneous burst discharges (Fig. 3D).

In similarity to $\mathrm{NE}$, application of $\mathrm{ACh}$ or $\mathrm{MCh}(n=13$ of 15) or ACPD ( $n=28$ of 30 ) to burst-generating neurons resulted in a depolarization of the membrane potential and a change to the single-spike mode of action potential generation (see Figs. $7,9)$. Prior to the change in firing mode, the rate of rhythmic burst generation increased in many, but not all, cells (see Fig. $7 B$ ). In addition, in many cells the initial response to $\mathrm{MCh}$ or ACh was a brief $(2-5 \mathrm{sec})$ hyperpolarization of the membrane potential and decreased burst firing, presumably resulting from cholinergic excitation of neighboring interneurons (see McCormick and Prince, 1986). Hyperpolarization of the membrane potential during the generation of single-spike firing in response to $\mathrm{MCh}$ or ACPD resulted in a return of rhythmic burst firing (e.g., Figs. 7, 9), indicating that the changes in firing mode are probably mediated by depolarization of the cells.

Although not the focus of the present study, the effects of application of $\mathrm{NE}, \mathrm{MCh}$, and ACPD were also examined on a 


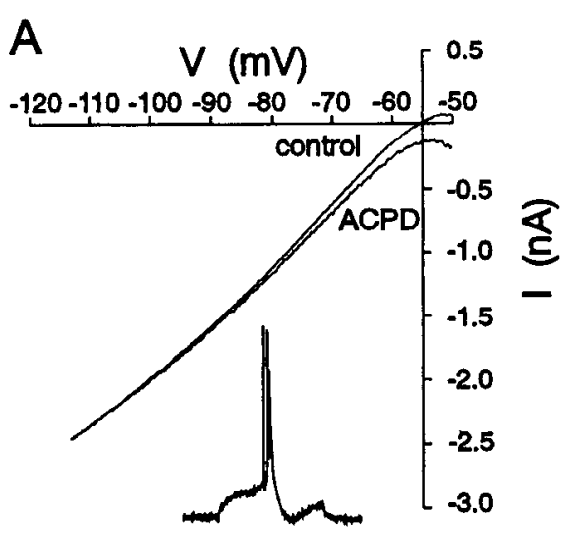

D ACPD minus Control

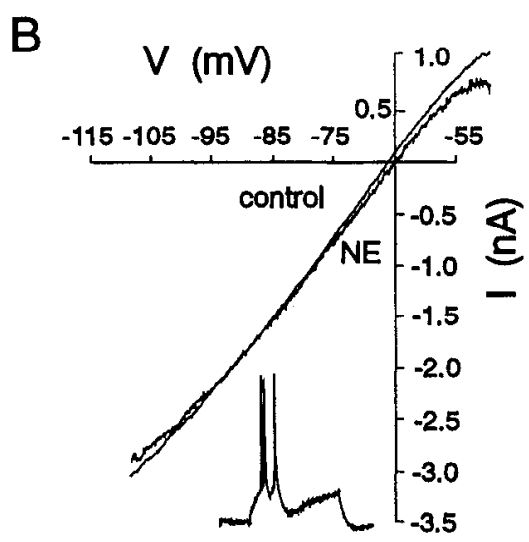

E NE minus Control

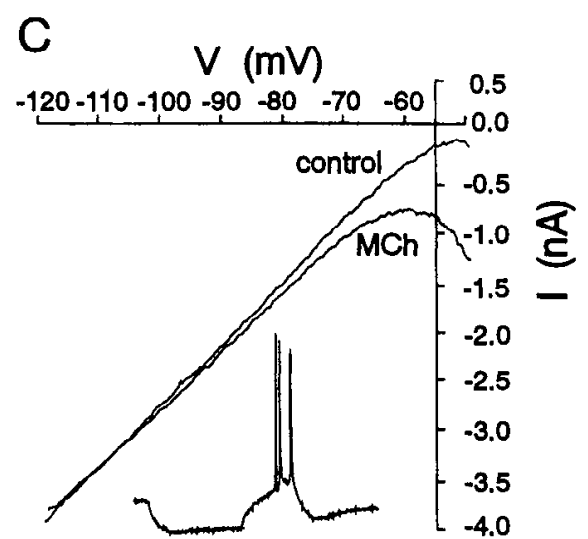

F MCh minus Control
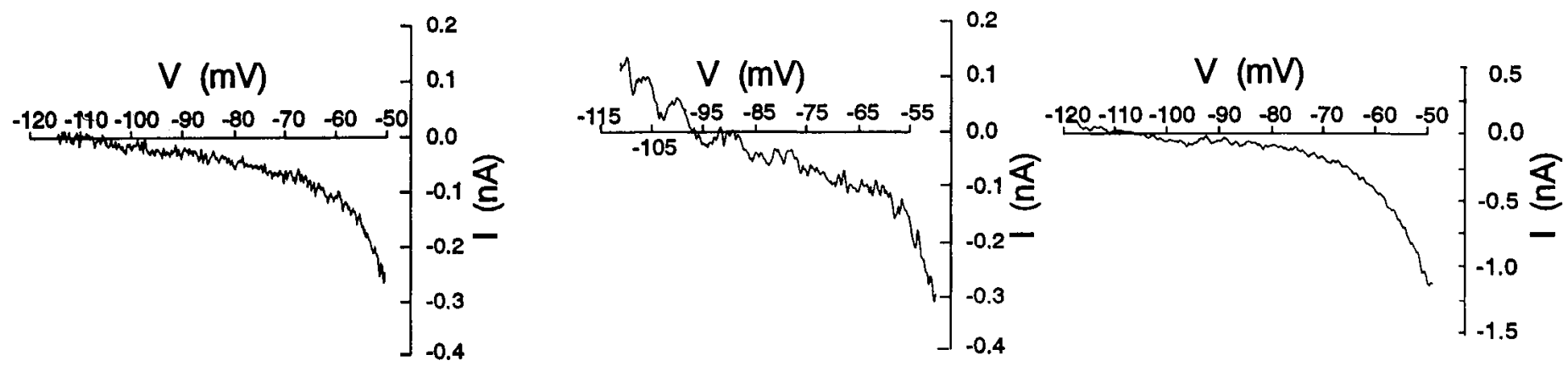

Figure 4. Voltage dependency of the responses to ACPD, NE, and MCh. $A-C$, Current versus voltage plots obtained in three different layer V burst-generating neurons before and after application of ACPD, NE, or MCh. $D-F$, Voltage dependence of current affected by ACPD, NE, and $\mathrm{MCh}$ obtained by subtracting the control $I-V$ relationship from that obtained in the indicated drug. Application of all three agents results in the appearance of an inward current that has two prominent components: a linear component that reverses at -95 to $-105 \mathrm{mV}$, and a nonlinear component that increases in amplitude at membrane potentials positive to approximately $-65 \mathrm{mV}$.

number of so-called "regular-spiking" neurons in layer V. In similarity with burst-generating neurons, $\mathrm{MCh}(n=8)$ and ACPD $(n=12)$ applications resulted in a depolarization of these cells and a decrease in membrane conductance. Similar responses were also found to NE in some cells ( $n=10$ of 16 ), suggesting that the ionic responses investigated here are not restricted to layer $\mathrm{V}$ burst-generating neurons.

Characterization of the ionic currents underlying the NE-, $A C h$-, and $A C P D$-induced depolarization

The ionic mechanisms of the slow depolarization resulting from the activation of $\alpha_{1}$-adrenergic, muscarinic, and glutamate metabotropic receptors were investigated by examining the effects of activation of these three classes of receptors on the apparent input conductance measured in current- and voltage-clamp modes, and on the $I-V$ plots between approximately -50 and $-120 \mathrm{mV}$, as obtained under voltage-clamp conditions. In current-clamp recordings, compensation for the ACPD-, NE-, or $\mathrm{MCh}$-induced depolarizations with the intracellular injection of current revealed an apparent decrease in membrane conductance, suggesting that activation of these receptors may be decreasing a membrane conductance that is normally active at rest. In other regular-spiking cortical pyramidal cells, activation of $\beta$-adrenergic, muscarinic, and glutamate metabotropic receptors results in a suppression of the slow AHP that occurs after a train of action potentials (McCormick and Prince, 1986;
Schwindt et al., 1988; Charpak et al., 1990). However, in burstgenerating neurons, application of NE, ACh, or ACPD did not result in any detectable change in the burst AHP (see Figs. 7, 9), or intrinsic structure of the burst itself.

In voltage-clamp recordings, application of $\mathrm{NE}, \mathrm{MCh}$, or ACPD to burst-firing neurons (Fig. 4, insets) resulted in an apparent inward current that reversed to an outward current around the presumed equilibrium potential for $\mathrm{K}^{+}$ions (approximately $-100 \mathrm{mV}$ in $2.5 \mathrm{~mm}\left[\mathrm{~K}^{+}\right]_{o}$; McCormick and Williamson, 1989). The average reversal potential for the $\mathrm{MCh}$ induced response $(-99.3 \pm 5.0 \mathrm{mV} ; n=6)$ was similar to that induced by NE $(-95.3 \pm 4.2 \mathrm{mV} ; n=3)$ and ACPD $(-99.2$ $\pm 5.3 \mathrm{mV} ; n=7)$. The decrease slope of the $I-V$ plot after application of $\mathrm{MCh}, \mathrm{NE}$, or ACPD indicates that this response is associated with a decrease in apparent input conductance. This, and the finding that the reversal potential is around $E_{K}$, suggests that this response is mediated at least in part through a decrease in a $\mathrm{K}^{+}$conductance. Subtraction of the $I-V$ plot obtained after application of $\mathrm{MCh}, \mathrm{NE}$, or ACPD from control revealed two prominent components of the response to all three of these agonists. Between membrane potentials of -120 and $-65 \mathrm{mV}$, the response to these three agonists appeared relatively linear, while at membrane potential positive to approximately $-65 \mathrm{mV}$, the amplitude of the response increased substantially (Fig. $4 D-F$ ). These results may be explained by the presence of two distinct currents that are altered by these neurotransmitters, 
A

a normal

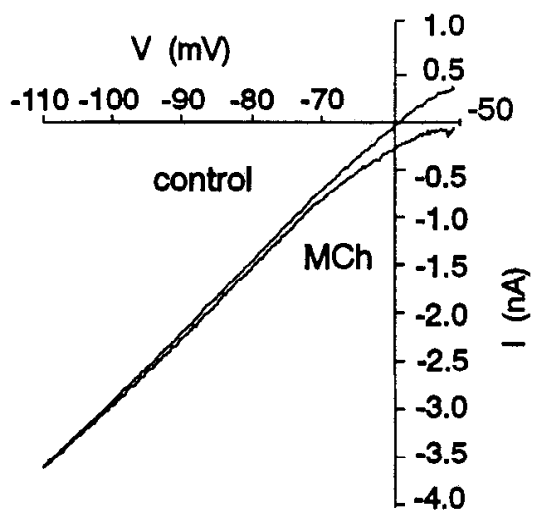

b MCh minus control

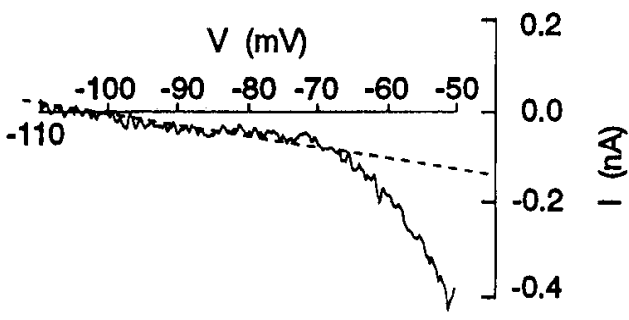

c synaptic stimulation

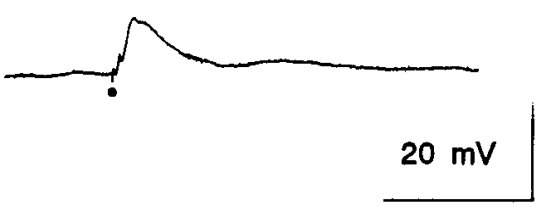

B

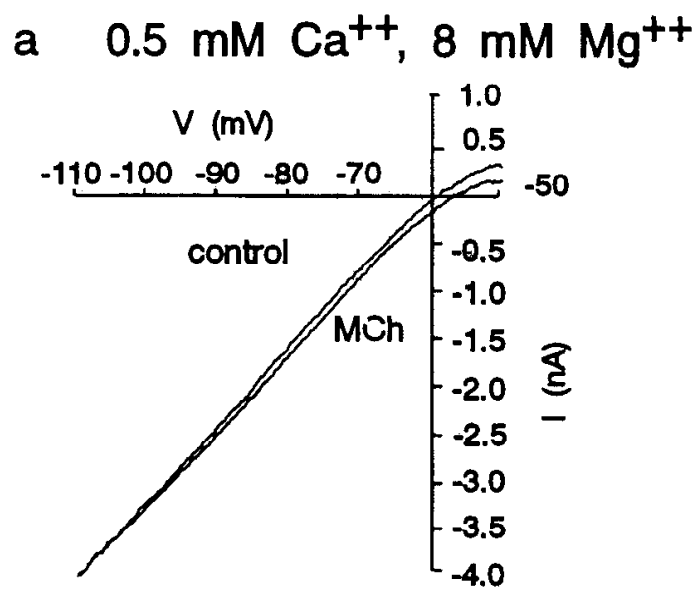

b MCh minus control

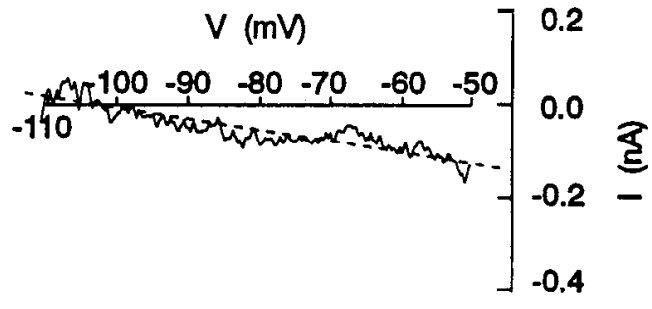

c synaptic blockade

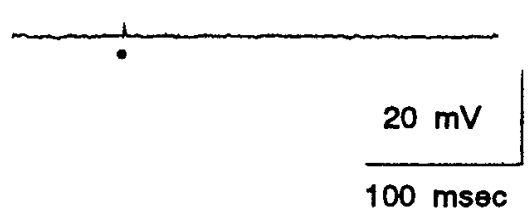

Figure 5. Effects of reduction of extracellular $\left[\mathrm{Ca}^{2+}\right]$ on responses to muscarinic receptor stimulation. $A$, Application of MCh to this layer $\mathrm{V}$ cell results in an inward current and a decreased slope of the $I-V$ plot $(a)$, indicating a decrease in conductance. Subtraction of the MCh $I-V$ plot from control gives the voltage sensitivity of the response $(b)$. There appears to be both a linear (broken line) and a nonlinear component. Electrical stimulation of afferent fibers results in a typical postsynaptic potential in this cell $(c)$, which was used as a test for the presence of synaptic transmission. $B$, Reducing $\left[\mathrm{Ca}^{2+}\right]_{o}$ from 2 to $0.5 \mathrm{mM}$ and increasing $\left[\mathrm{Mg}^{2+}\right]_{o}$ from 2 to $8 \mathrm{mM}$ result in block of synaptic transmission $(c)$ and a block of the voltage-dependent, but not the linear, component of the response to $\mathrm{MCh}(a, b)$.

although a single current with complicated voltage dependence is also possible.

In other neuronal systems, activation of noradrenergic, cholinergic, and glutamatergic receptors has been associated with decreases in $\mathrm{Ca}^{2+}$-activated $\mathrm{K}^{+}$currents, particularly the slow $\mathrm{Ca}^{2+}$-activated $\mathrm{K}^{+}$current known as $I_{\mathrm{AHP}}$ (Madison and Nicoll, 1986; Schwindt et al., 1988; McCormick and Williamson, 1989; Charpak et al., 1990). We tested the $\mathrm{Ca}^{2+}$ dependency of the present responses by reducing $\left[\mathrm{Ca}^{2+}\right]_{o}$ from 2 to $0.5 \mathrm{~mm}$ and increasing $\left[\mathrm{Mg}^{2+}\right]_{0}$ from 2 to $6-8 \mathrm{mM}$, thereby strongly reducing or blocking the transmembrane flow of $\mathrm{Ca}^{2+}$ ions. This procedure also had the additional benefit that block of $\mathrm{Ca}^{2+}$ currents also blocks synaptic transmission and therefore tests whether or not the observed responses are mediated through the $\mathrm{Ca}^{2+}$ dependent release of other neuroactive substances.

Reduction of $\left[\mathrm{Ca}^{2+}\right]_{o}$ and increasing $\left[\mathrm{Mg}^{2+}\right]_{o}$ resulted in a block of synaptic transmission but did not block the inward current response to $\mathrm{NE}, \mathrm{ACh}$, or ACPD, indicating that these agonists are having their effects directly on the recorded cell. However, examination of the agonist-sensitive current before and after reduction of $\left[\mathrm{Ca}^{2+}\right]_{o}$ revealed that the voltage-dependent component of the ionic response was abolished in reduced $\left[\mathrm{Ca}^{2+}\right]$ solution (Fig. $5 ; n=5$ ). This result indicates that either the voltage-dependent ionic current that is blocked by agonist application is dependent upon the entry of $\mathrm{Ca}^{2+}$ into the postsynaptic cell for its activation, or that the process by which receptor activation results in current suppression is in some manner disrupted by reduction of $\left[\mathrm{Ca}^{2+}\right]_{o}$ and raising $\left[\mathrm{Mg}^{2+}\right]_{o}$. These possibilities remain to be explored in detail.

The possibility that the reduction of $\left[\mathrm{Ca}^{2+}\right]_{o}$ may block the voltage-dependent component through a block of synaptic release of another neuroactive agent was tested through the block 

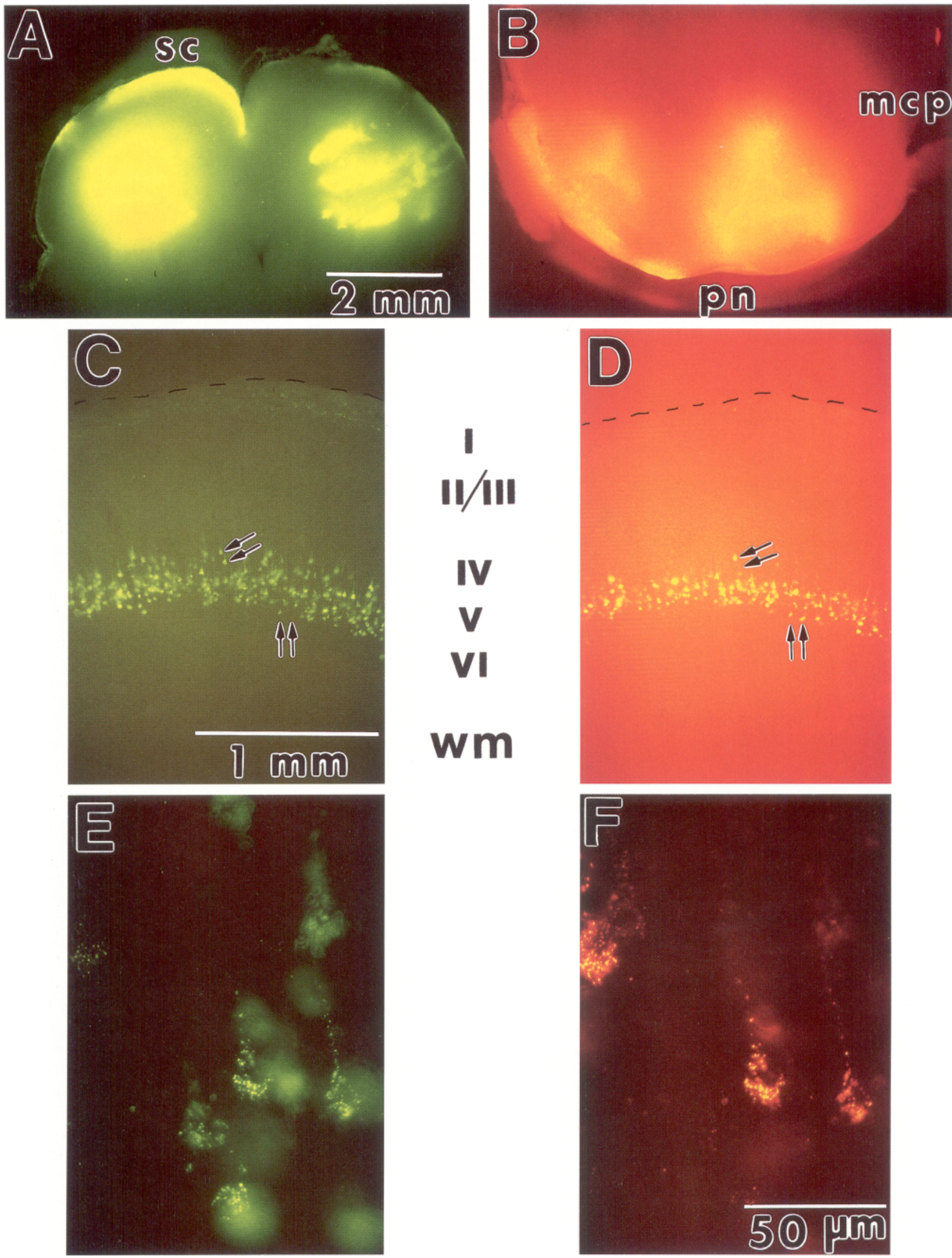
of synaptic transmission with local application of TTX (10 $\mu \mathrm{M}$ in micropipette). Block of synaptic transmission in this manner did not block the voltage-dependent component to activation of muscarinic and glutamate metabotropic receptors, suggesting that the blocking effect of reduction of $\left[\mathrm{Ca}^{2+}\right]_{o}$ is not due to a block of synaptic transmission.

\section{Subcortical projections of burst-generating neurons}

Previous investigations of the morphology of burst-generating neurons in primary visual cortex have revealed these cells to be large layer $\mathrm{V}$ pyramidal cells possessing apical dendrites that extend into layer $I$ and have a morphology similar to layer $V$ pyramidal cells known to project to the superior colliculus and or pontine nuclei (Chagnac-Amitai and Connors, 1989; Larkman and Mason, 1990; Kasper et al., 1991). To test the possibility that the NE-, ACh-, and ACPD-sensitive burst-generating neurons studied here may include superior colliculus- and pontine nucleus-projecting neurons, we retrogradely labeled these cells with the injection of rhodamine fluorescent microspheres (Katz et al., 1984; Katz and Iarovici, 1990) into either the superior colliculus or pontine nuclei prior to recording from layer $\mathrm{V}$ burst-generating neurons with microelectrodes containing Lucifer yellow $\mathrm{CH}$.

Injection of fluorescent microbeads into either the superior colliculus or the pontine nuclei resulted in marked labeling of layer V cells (Fig. 6). Many of these cells were labeled well enough to reveal an apical dendrite under close examination (e.g., Fig. $6 E, F$ ), suggesting that they are pyramidal in morphology. Double injections in the same animals, such as rhodamine bead injection into the pontine nuclei and green fluorescent microbeads into the superior colliculi, resulted in labeling within overlapping portions of layer $\mathrm{V}$ (compare Fig. $6 C, D$ ). Gross examination of these sections revealed the presence of numerous cells that contained both the rhodamine and green microbeads (e.g., Fig. $6 C-F$ ), as well as cells that contained only one type of bead or the other (scc arrows, Fig. 6C,D). Although the percentage of cells that project to both the pontine nuclei and superior colliculus could not be quantified, owing to the quite variable degree of labeling of layer $\mathrm{V}$ cells after varying levels of labeling of the injection site, our impression was that a significant percentage of layer $\mathrm{V}$ pyramidal cells project to both areas, in agreement with the results of Hallman et al. (1988) obtained in rat.

Intracellular recordings were successfully obtained from 22 retrogradely labeled superior colliculus-projecting neurons (Figs. $7,8)$. Electrophysiologically all of the cells were similar in that they generated a complex of two to six action potentials followed by a pronounced AHP in response to a threshold depolarizing current pulse at resting membrane potentials (Fig. 7, 8). However, under closer examination, it was also clear that these cells demonstrated a continuum of responses to depolarizing current pulses ranging from frank burst generation (Figs. 7, 8;n=8) to doublet firing (e.g., see Fig. 10; $n=7$ ), with some cells dem- onstrating a behavior intermediate between bursting and doublet firing (not shown).

Application of NE $(n=3)$, MCh $(n=3)$, or ACPD $(n=3)$ to identified superior colliculus-projecting cells resulted in a pronounced depolarization and change in firing mode from one of burst generation to single-spike activity (Fig. 7). Compensation for this slow depolarization with the intracellular injection of current changed the firing mode of these cells back to burst generation, indicating that this change in firing mode resulted merely from depolarization of the cell (Fig. 7, -d.c.).

The morphological features of superior colliculus-projecting cells in the guinea pig were similar to those described previously for the rat and cat (Hallman et al., 1988; Hüberner et al., 1990). The most prominent feature of these cells was the presence of a prominent apical dendrite that ended in a terminal tuft in layer I (Fig. 8). The apical and basilar dendrites of all of the double-labeled corticotectal neurons were quite spinous (Fig. 8).

Injection of fluorescent microbeads into the pontine nuclei resulted in dense retrograde labeling cells in layer $\mathrm{V}$ of primary visual cortex (Fig. 6D). Intracellular recordings of burst- or doublet-firing neurons resulted in the recording from 15 beadcontaining pontine-projection cells. In the present study, the recorded pontine-projecting cells were characterized electrophysiologically as bursting cells generating a complex of three to five action potentials in response to a threshold depolarizing current pulse $(n=8)$, as doublet-firing cells in which the cell generated at threshold two closely spaced action potentials followed by an AHP (e.g. Fig. 10; $n=5$ ), or discharging in a manner intermediate between bursting and doublet firing (e.g., Fig. $9 C$; $n=2$ ). In similarity with corticotectal cells, depolarization of identified corticopontine neurons with the intracellular injection of current typically resulted in a change in firing mode from rhythmic burst firing to tonic, single-spike activity (not shown).

Application of NE $(n=2)$, MCh $(n=3)$, or ACPD $(n=5)$ to pontine nuclei-projecting layer $\mathrm{V}$ pyramidal cells resulted in depolarization and a change in firing mode. Again, this effect was mimicked by depolarization of the cell with the intracellular injection of current (not shown), or negated by hyperpolarization during the response back to predrug membrane potential (Fig. $9,-$ d.c.). As with corticotectal cells, corticopontine layer $\mathrm{V}$ cells were pyramidal in morphology and possessed an apical dendrite that bifurcates extensively in layer I (Fig. 10).

\section{Discussion}

Morphological and electrophysiological features of corticotectal and corticopontine neurons

Layer $\mathrm{V}$ pyramidal cells in the mammalian sensorimotor and primary visual neocortex form the major output pathway for these cortical regions to subcortical nonthalamic structures, projecting to the superior colliculus and pontine nuclei, among other targets (Gilbert and Kelly, 1975; Wise and Jones, 1977; Schofield et al., 1987; Hallman et al., 1988). In addition, a subset of layer $\mathrm{V}$ pyramidal cells in both the primary visual and somato-

\footnotetext{
Figure 6. Identification of layer V pyramidal cells that project to either the superior colliculi or the pontine nuclei in the guinea pig. $A$, Injection site of green fluorescent beads into the superior colliculi. $B$, Injection site of rhodamine fluorescent beads in the pontine nuclei of the same animal as in $A$. C. Location of cells in primary visual cortex in layer $\mathrm{V}$ that project to the superior colliculus. $D$, Location of cells that project to the pontine nuclei. Double arrows indicate cells that are labeled by both injections (top arrow in upper set and left arrow in lower set), or by the superior colliculus injection only (bottom arrow in upper set) or the pontine nuclei injection only (right arrow in bottom set). Cells labeled with green or rhodamine beads or both are therefore easily distinguished from one another. $E$ and $F$, Example of double- and non-double-labeled cells under higher magnification.
} 

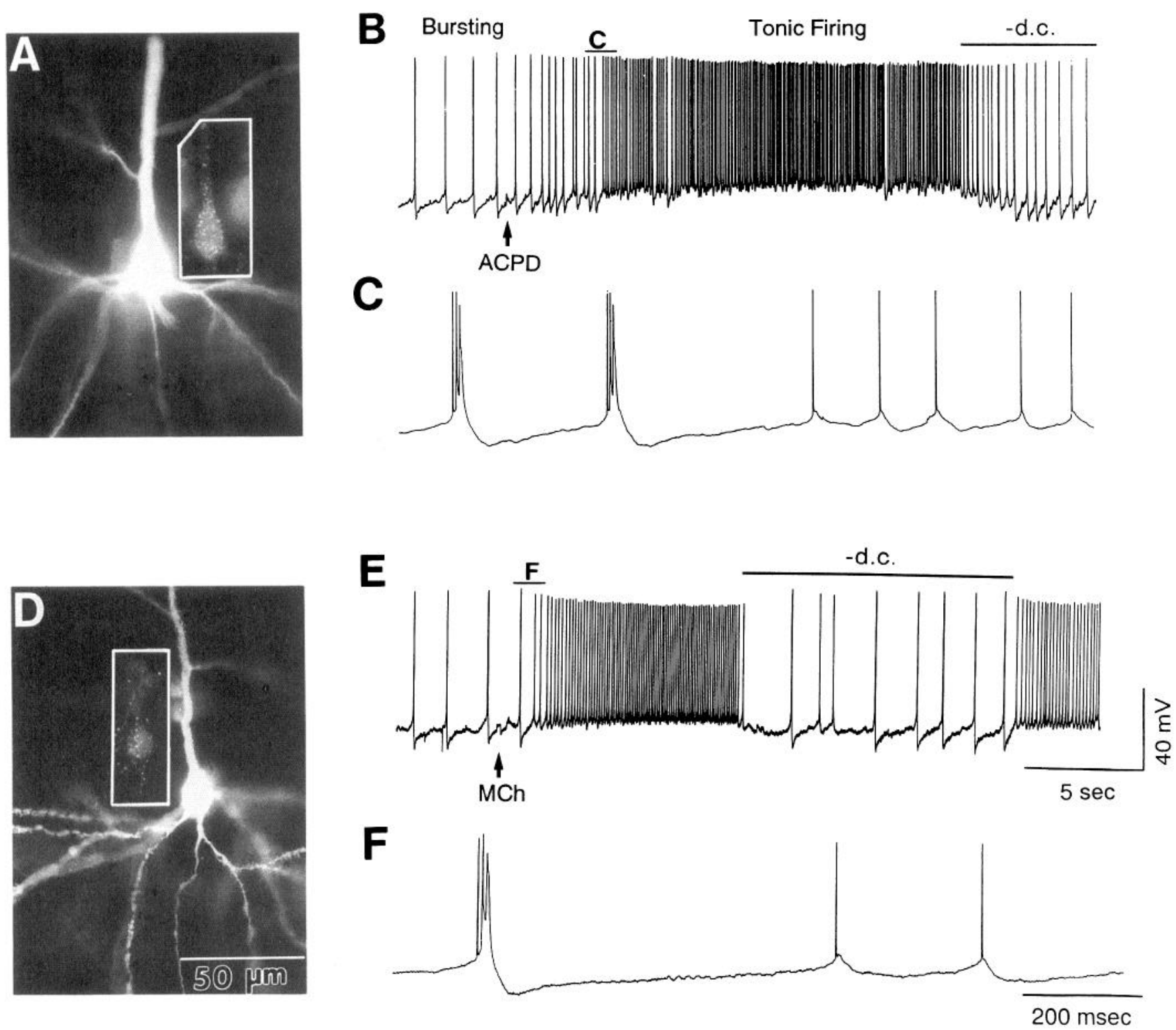

Figure 7. Response of superior colliculus-projecting layer $\mathrm{V}$ pyramidal cells to activation of glutamate metabotropic and muscarinic receptors. $A$, Morphology and presence of rhodamine beads in a layer $\mathrm{V}$ pyramidal cell recorded with a microelectrode containing Lucifer yellow. $B$, Recording from cell of $A$. Application of ACPD results initially in an increase in the rate of burst firing followed by a switch to the single-spike mode of action potential generation (Tonic Firing). Intracellular injection of current ( - d.c.) negates this change in firing mode and reinstates rhythmic burst firing. $C$, The switch in firing mode illustrated for detail. $D$, Morphology and presence of rhodamine beads in another layer $\mathrm{V}$ pyramidal cell. $E$, Application of the muscarinic agonist MCh results in depolarization and change in firing mode from rhythmic bursting to tonic, single-spike activity. Hyperpolarization of the cell with intracellular injection of current $(-$ d.c.) reinstates rhythmic burst firing. $F$, Switch in firing mode shown in detail.

sensory cortices also project callosally to contralateral cortical areas (e.g., Hallman et al., 1988). Analysis of the morphological features of the cells that give rise to descending projections to the superior colliculus has revealed that these neurons are medium to large pyramidal cells that possess an extensive "skirt" of basal dendrites surrounding the cell body within layer V and an apical dendrite that extends to, and bifurcates in, layer I. The axons of corticotectal cells typically give rise to collaterals that travel laterally within layers V and VI and give rise to numerous en passant synaptic connections with other pyramidal and nonpyramidal cells, suggesting that together layer $V$ pyramidal cells, and perhaps layer VI pyramidal cells, form an interconnected sheet of subcortically projecting neurons through which primary visual and somatosensory cortices may directly influence the pattern of activity generated by superior collicullar, pontine, and thalamic neurons (Gilbert and Wiesel, 1979; Gabbott et al., 1987; Hallman et al., 1988; Chagnac-Amitai et al., 1990). In confirmation of these earlier morphological findings, we also found that in the guinea pig cells that project to the superior colliculus from area 17 are layer $\mathrm{V}$ pyramidal cells possessing an apical dendrite that extends to, and bifurcates extensively throughout, layer I (Fig. 8) and possessing an axon that gives rise to collaterals that travel laterally within layers V and VI (not shown). Similarly, cells in guinea pig area 17 that project to the pontine nuclei were also found to be spinous pyramidal cells possessing an apical dendrite extending to layer I (Fig. 10). 

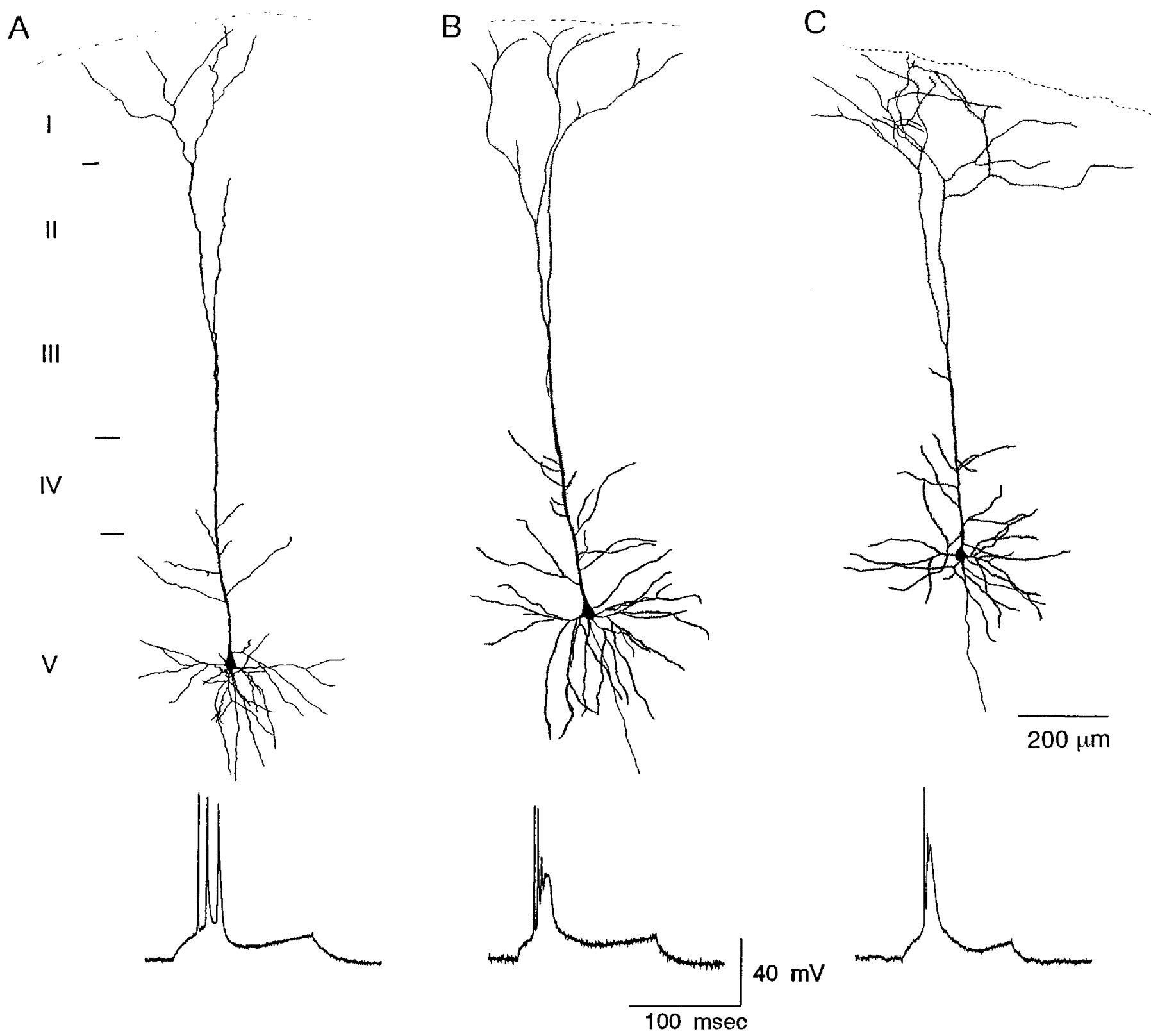

Figure 8. Camera lucida reconstructions of superior colliculus-projecting pyramidal cells. All three cells were characterized electrophysiologically as burst generating. The cell in $B$ is a reconstruction of the cell in Figure $7 A$. Cell in $C$ responded to NE and MCh with a change in firing mode from spontaneous bursting to single-spike activity. Example of response of each cell to injection of a depolarizing current pulse is illustrated below each reconstruction.

In the present study, we demonstrate that layer $\mathrm{V}$ corticopontine and corticotectal cells not only possess distinct morphological features, but also exhibit distinct electrophysiological properties that may be modulated by neurotransmitter actions.

Intracellular recordings in vitro of ncurons in the rodent somatosensory, visual, and cingulate cortical regions have revealed a heterogeneity of intrinsic electrophysiological properties. Three broad classes of neurons that were distinguished early on are the "regular-spiking," "burst-generating," and "fast-spiking" neurons. Morphological analysis of these different electrophysiological categories has revealed that the regular-spiking neurons are pyramidal cells throughout layers II-VI, burst-generating neurons are pyramidal cells located mainly in layer $\mathrm{V}$, and fast-spiking neurons are nonpyramidal cells located throughout layers II-VI (Connors et al., 1982; McCormick et al., 1985). More detailed comparison of the morphological features of regular-spiking and burst-generating pyramidal cells has revealed that although regular-spiking pyramidal cells form a morphologically heterogeneous group that includes the "typical" apical dendrite-possessing pyramidal cells of layers II-VI as well as inverted pyramidal and polymorphic cells of layer VI (McCormick et al., 1985; van Brederode and Snyder, 1992), burst-generating pyramidal cells are less heterogeneous (although not homogeneous), being typified as medium- to largesize pyramidal cells in layer $\mathrm{V}$ that possess a "thick" apical dendrite that extends to and bifurcates extensively in layer I (Chagnac-Amitai et al., 1990; Larkman and Mason, 1990). The similarity of the morphological features of burst-generating layer $\mathrm{V}$ cells and corticotectal and corticopontine cells suggests that burst-generating cells may project to these subcortical regions. 

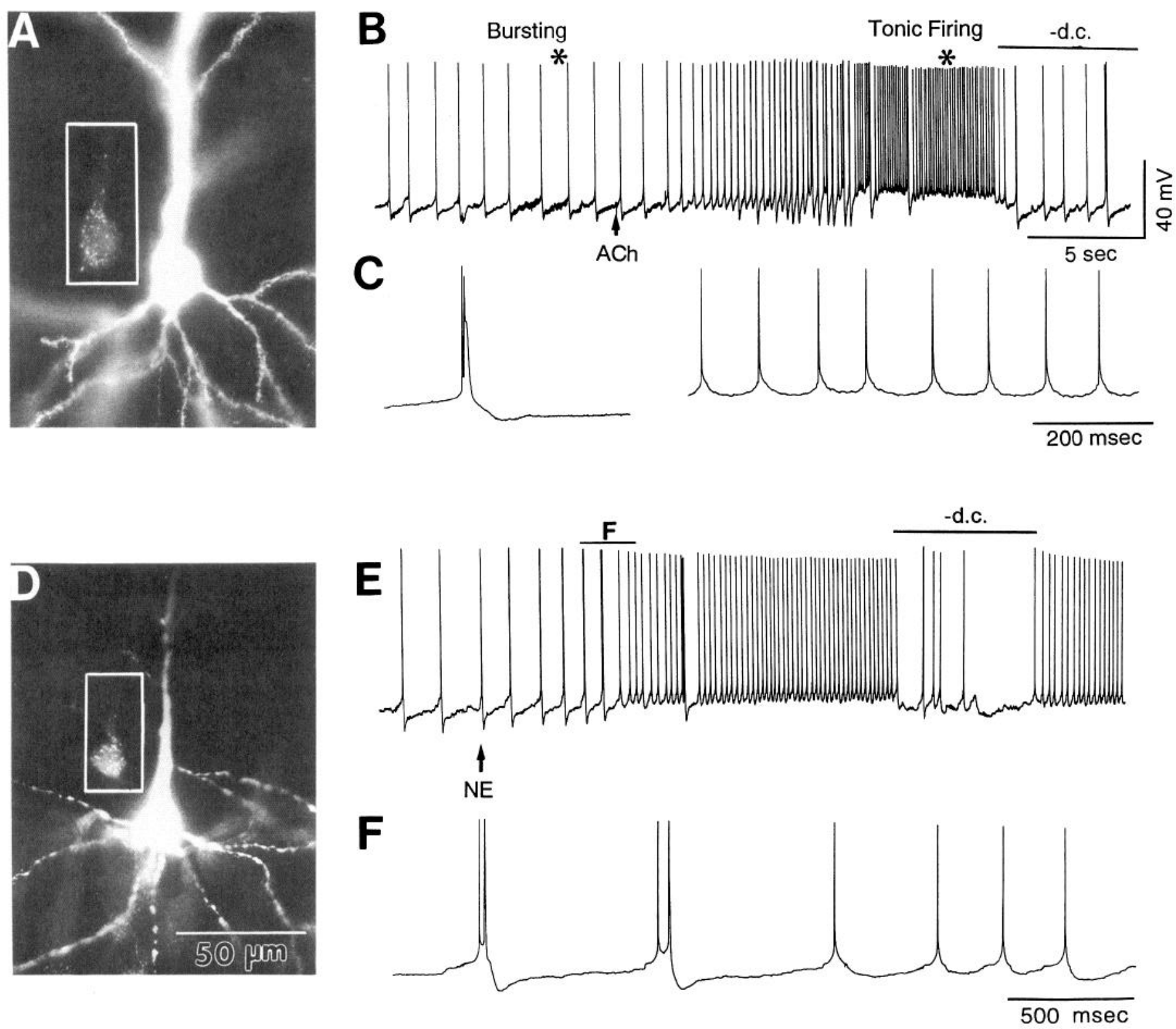

Figure 9. Responses of identified pontine nuclei-projecting layer V cells to ACh and NE. A, Morphology and presence of rhodamine beads of a layer V pyramidal cell after labeling of pontine nuclei. $B$, Intracellular recording of cell in $A$ and response to ACh. Application of ACh results in an increase in the rate of rhythmic burst firing followed by a switch to the single-spike mode of action potential generation (Tonic Firing). Hyperpolarization of the membrane potential with the intracellular injection of current $(-d . c$.) negated the change in firing mode. $C$, Examples of burst and tonic firing (asterisks in $B$ ). $D$, Morphology and presence of rhodamine beads in another layer $\mathrm{V}$ pyramidal cell that projects to the pontine nuclei. The beaded appearance of the dendrite in this cell most likely represents morphological damage from prolonged iontophoretic injection of Lucifer yellow. This cell is included here to demonstrate the response to NE application. $E$, Application of NE to the cell in $D$ results in an initial increase in doublet firing and a switch to the single-spike mode of action potential generation. Hyperpolarization of the cell with the intracellular injection of current $(-$ d.c.) resulted in a reappearance of doublet firing. $F$, Expansion of indicated portion of recording in $E$ illustrates spontaneous doublet firing and change in firing mode.

Indeed, in an intracellular in vitro recording study of identified superior colliculus- and pontine nuclei-projecting cells of the rat primary visual cortex, Kasper and colleagues have reported that these cells are burst-generating neurons and possess morphological features previously associated with subcortically projecting layer V cells, while callosally projecting layer V cells are "regular-spiking" pyramidal cells and have their own distinct morphological features (Kasper et al., 1991). Similarly, we report here that at least some layer $\mathrm{V}$ burst-generating neurons in the guinea pig visual cortex project to either the superior col- liculus or the pontine nuclei (Figs. 7-10). However, in addition to neurons that meet the established criteria of "intrinsic bursting" (generation of a complex of three or more action potentials to a threshold depolarizing current pulse), we also found that many corticotectal and corticopontine layer $\mathrm{V}$ pyramidal cells generate either only a "doublet" of action potentials to a threshold current pulse, or an electrophysiological response that is intermediate between burst and doublet firing. Although we have not compared the morphological features of "doublet" and "bursting" cells in detail, their gross similarity in morphology 
A
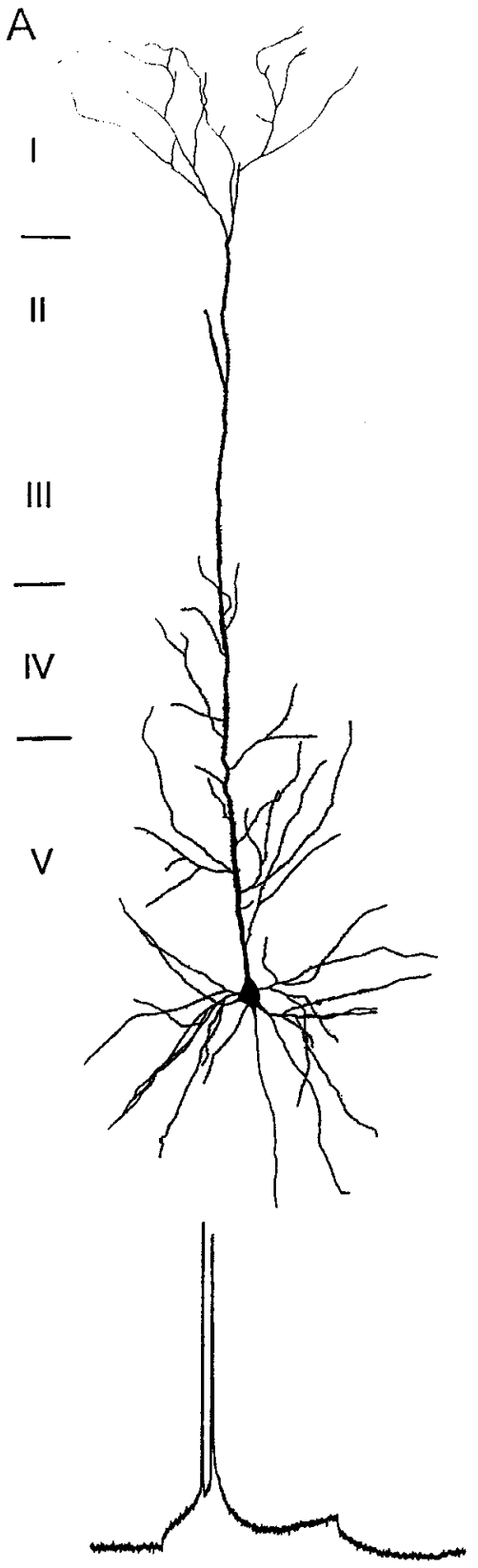

B

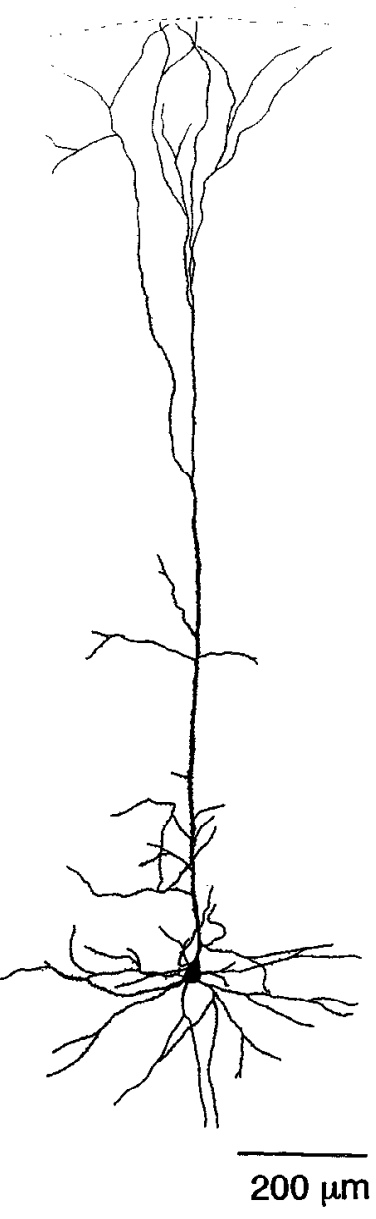

C
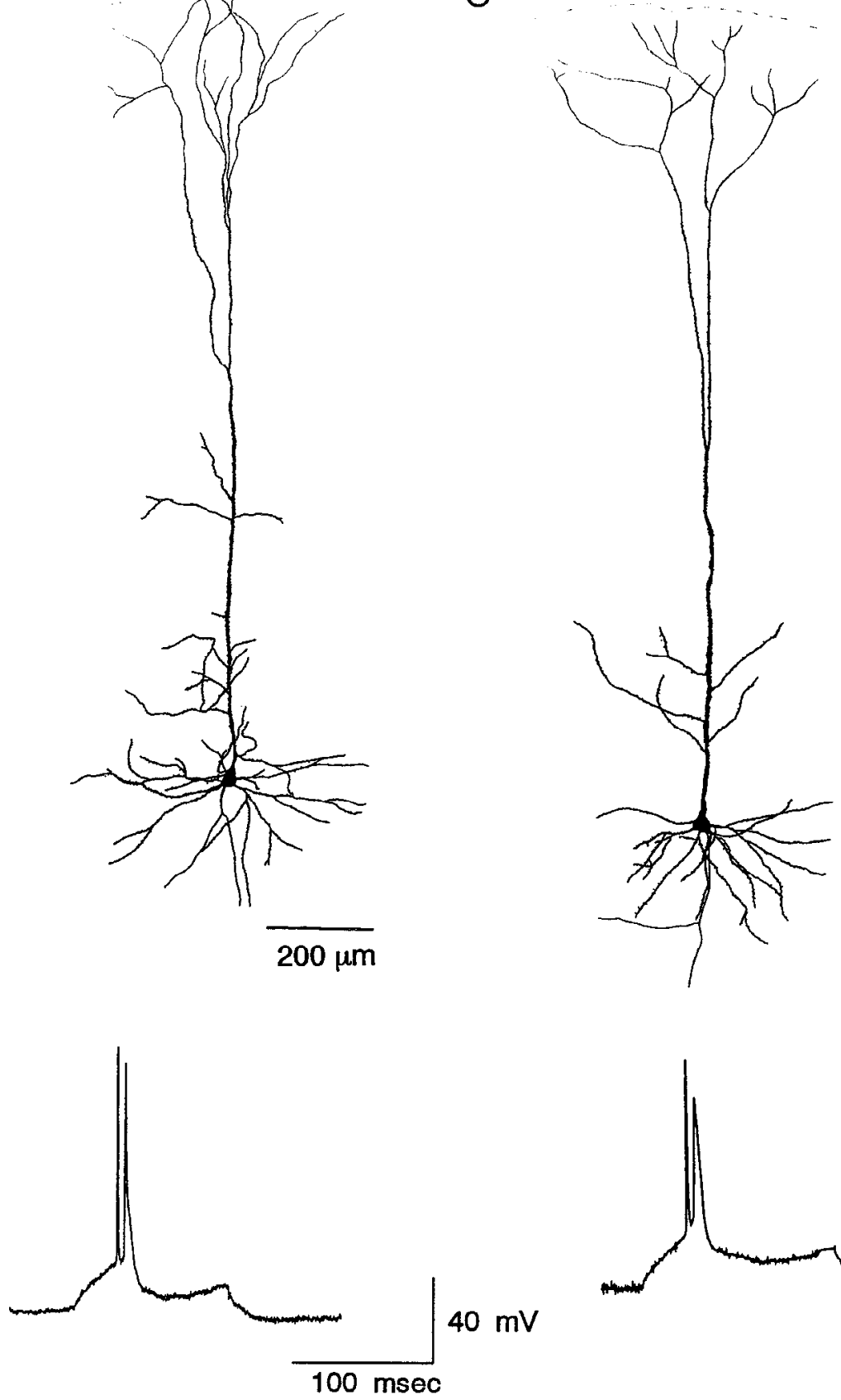

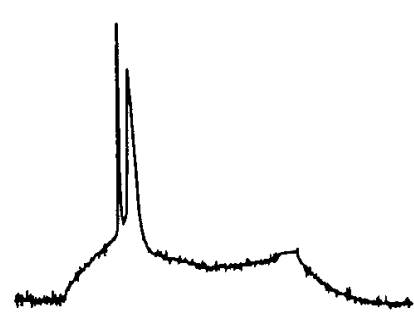

Figure 10. Camera lucida reconstructions of layer V corticopontine pyramidal cells in primary visual cortex. Each cell illustrated was retrogradely labeled with rhodamine beads and generated a "doublet" of action potentials in response to depolarization. The cell illustrated in $C$ responded to ACPD with depolarization and the generation of spontaneous, single-spike activity.

suggests that "burst" generation represents a continuum that extends from the generation of two to six action potentials, as opposed to the previously defined three or more action potentials (McCormick et al., 1985). Indeed, the inclusion of "doublet-firing" cells into the burst-generating category is consistent with the findings of other investigations of intrinsic burst-generating neurons in the cerebral cortex (Sutor and Zieglgansberger, 1987; Montoro et al., 1988; Fochring et al., 1991). However, the inclusion of doublet-firing cells in the category of "burstgenerating" neurons may result in considerable confusion in the definition of electrophysiological subtypes in the cortex, since doublet-firing cells are found throughout all layers and are not confined to layer $\mathrm{V}$ while bursting cells that fire three or more action potentials are found predominately in this layer (Connors, 1984; McCormick et al., 1985). Therefore, in order to avoid confusion, cells generating a complex of two action potentials to a depolarizing current pulse should be referred to as "doublet-firing" and not as "burst-generating" cells. Recently, Tseng et al. (1991) have demonstrated that layer V corticospinal pyramidal neurons in the rat sensorimotor cortex may be burstgenerating as well as non-burst-generating, indicating that burstgenerating layer $\mathrm{V}$ cells project to the spinal cord as well and that physiological heterogeneity may characterize descending pathways. 


\section{Functional consequences of neuromodulation of corticotectal and corticopontine neurons}

Extracellular current source density analysis of delta wave generation in the cerebral cortex reveals a current sink around layer $\mathrm{V}$, suggesting that cells in this layer may play a role in the generation of slow waves (Ball et al., 1977; Rappelsberger et al., 1982). Indeed, extracellular and intracellular recordings from layer V cells have revealed an increased, followed by a decreased, propensity to generate action potentials during the generation of each wave (Creutzfeldt et al., 1966; Ball et al., 1977). In our recordings, layer $\mathrm{V}$ burst-generating neurons typically exhibited rhythmic burst firing in the frequency range of $0.2-10 \mathrm{~Hz}$, depending upon the level of depolarization of the cell (Wang and McCormick, 1992). These results suggest that burst-generating neurons are well equipped to participate in rhythmic synchronized slow activity such as that which occurs during delta waves. Recently Silva et al. (1991) have demonstrated in vitro that layer $V$ contains within it the neuronal machinery necessary and sufficient to generate brief periods of oscillatory field potentials in the frequency range of $5-10 \mathrm{~Hz}$ in response to activation of excitatory afferents. Intracellular recording of this activity demonstrates that it is associated with rhythmic burst firing in burstgenerating layer $\mathrm{V}$ cells, suggesting that these neurons may have an important role in the generation of this activity (Silva et al., 1991). Indeed, previous investigations by Connors and colleagues have implicated layer $\mathrm{V}$ in the generation and spread of another type of cortical rhythmic activity: epileptiform paroxysmal discharge during reduced GABAergic inhibition (Connors, 1984; Chagnac-Amitai and Connors, 1989). These authors propose that the intrinsic properties of layer $\mathrm{V}$ burst-generating neurons (rhythmic sequences of bursts separated by AHPs) and the interconnections of these neurons with other pyramidal cells and potentially other burst-generating cells in layer $V$ give these cells a natural propensity to generate epochs of oscillatory sequences of burst firing, which may then be rapidly communicated to other layers of cortex. In this manner, the layer $V$ burstgenerating cells of the cerebral cortex may play a role similar to that which has been proposed for the CA3 pyramidal cells of the hippocampus in the synchronization and spread of oscillatory or paroxysmal activity (e.g., see Wong and Traub, 1983).

Numerous pharmacological, electrophysiological, and lesion studies have demonstrated the disappearance of slow waves from the EEG in the transition to the waking and attentive state and the dependence of this block of slow-wave generation on the actions of modulatory neurotransmitters, particularly ACh (Phillis, 1968; Buzsáki et al., 1988; see reviews by Vanderwolf, 1988; Steriade and McCarley, 1990). If layer V pyramidal cells are involved in the generation of slow waves, one may then expect that application of these neurotransmitters may modulate the firing mode of these cells in a manner consistent with the block of slow-wave generation and the promotion of tonic activity. Our results, and those of others, are consistent with this hypothesis. In the guinea pig, autoradiographic localization of $\alpha_{1}$-adrenoceptors reveals a dense band throughout the cerebral cortex, with the highest densities in layers IV and V (Jones et al., 1985). Similarly, the autoradiographic localization of muscarinic receptors in the rat reveals the presence of these receptors in both supcrficial and decp layers of cortex (Cortés and Palacios, 1986; Mash and Potter, 1986). Examination of the cholinergic innervation of rat somatosensory and visual cortical regions reveals that fibers positive for the presence of ChAT are prom- inent in layer $\mathrm{V}$ of both somatosensory and visual cortical regions and that these fibers make synaptic contacts on both pyramidal and nonpyramidal cells (Houser et al., 1985; Eckenstein et al., 1988; Lysakowski ct al., 1989). Similarly, the rodent visual and somatosensory cortical areas are innervated by presumed noradrenergic fibers with considerable innervation of layer $\mathrm{V}$ in both of these cortical regions (reviewed in Morrison and Magistretti, 1983; Parnavelas and Papadopoulos, 1989).

Extracellular iontophoretic investigations of the actions of NE in the cerebral cortex have revealed both inhibitory and excitatory responses (Bevan et al., 1977; Waterhouse et al., 1981; Armstrong-James and Fox, 1983). Careful examination of the dose-response relationship and laminar location of excitatory responses reveals that infragranular cells exhibit a preponderance of excitatory responses to NE, particularly at low levels of iontophoretic application (Armstrong-James and Fox, 1983). Similarly, extracellular iontophoretic application of $\mathrm{ACh}$ in vivo is often associated with excitatory responses in infragranular neurons (reviewed in Krnjevic, 1975). Our present results confirm these extracellular in vivo recordings in that we find that activation of $\alpha_{1}$-adrenoceptors or muscarinic receptors on layer $\mathrm{V}$ neurons, particularly layer $\mathrm{V}$ burst-generating cells, results in a slow depolarization and increase in action potential discharge. Analysis of the voltage dependence and reversal potential of this response suggests that it may be mediated by the suppression of a least two separate ionic currents: a relatively voltage-independent $\mathrm{K}^{+}$current, and a voltage-dependent component whose sensitivity to receptor activation is blocked by removal of extracellular $\mathrm{Ca}^{2+}$ (Figs. 7, 8). More detailed investigations are required before the exact ionic characteristics of the voltagedependent component, or the possible presence of effects on other ionic currents, are known. We have previously demonstrated in thalamic relay cells the suppression of a relatively linear $\mathrm{K}^{+}$current in response to activation of $\alpha_{1}$-adrenergic, muscarinic, and glutamate metabotropic receptors (McCormick, 1991; McCormick and von Krosigk, 1992). In other cortical systems, suppression of voltage-dependent or voltage-independent $\mathrm{K}^{+}$currents through activation of these receptors has also been established (Halliwell and Adams, 1982; Madison et al., 1987; McCormick and Williamson, 1989; Charpak et al., $1990)$.

Functionally we demonstrate that the neurotransmitter-induced slow depolarization is capable of controlling the firing mode of cortical burst-generating neurons. The initial response that occurs to $\alpha_{1}$-adrenergic, muscarinic, or glutamate metabotropic receptor stimulation is often an increase in the rate of spontaneous burst generation (e.g., Fig. 7B) followed in most neurons by a switch to the single-spike mode of action potential generation (Fig. 11). These effects are mimicked by depolarization and negated by hyperpolarization (accomplished through the intracellular injection of current) and therefore are presumed to be mediated through simple depolarization of the cell. In this manner, the pattern and rate of activity generated by layer $\mathrm{V}$ burst-generating neurons may be controlled by the level of activation of $\alpha_{1}$-adrenergic, muscarinic, and glutamate metabotropic receptors. Increased release of these neurotransmitters may increase the level of depolarization of the membrane potential and subsequently control the pattern of activity generated by these cells and the neural circuits in which they participate. What might be the function of this effect of noradrenergic, cholinergic, and glutamate metabotropic receptor activation? Activity in cortical and thalamocortical circuits undergoes large 
A

Bursting Activity

Single Spike Activity

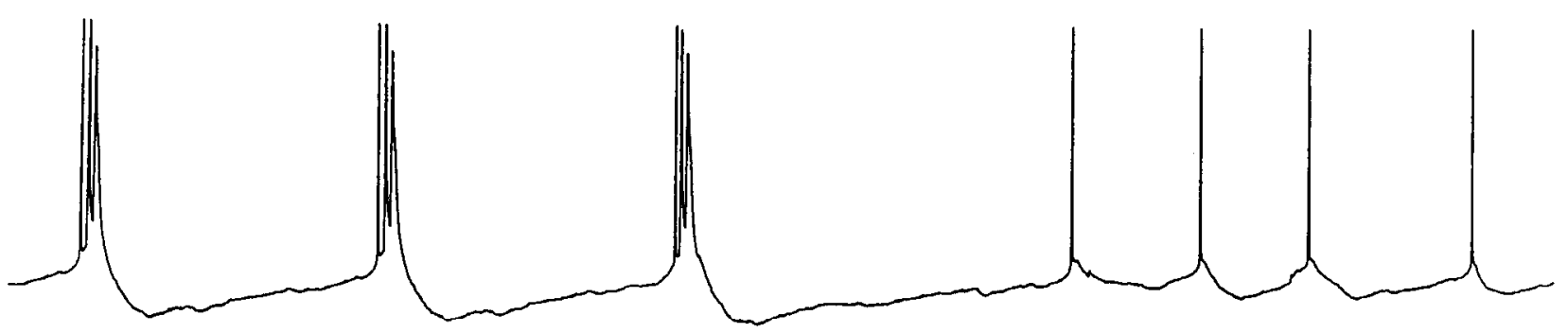

B

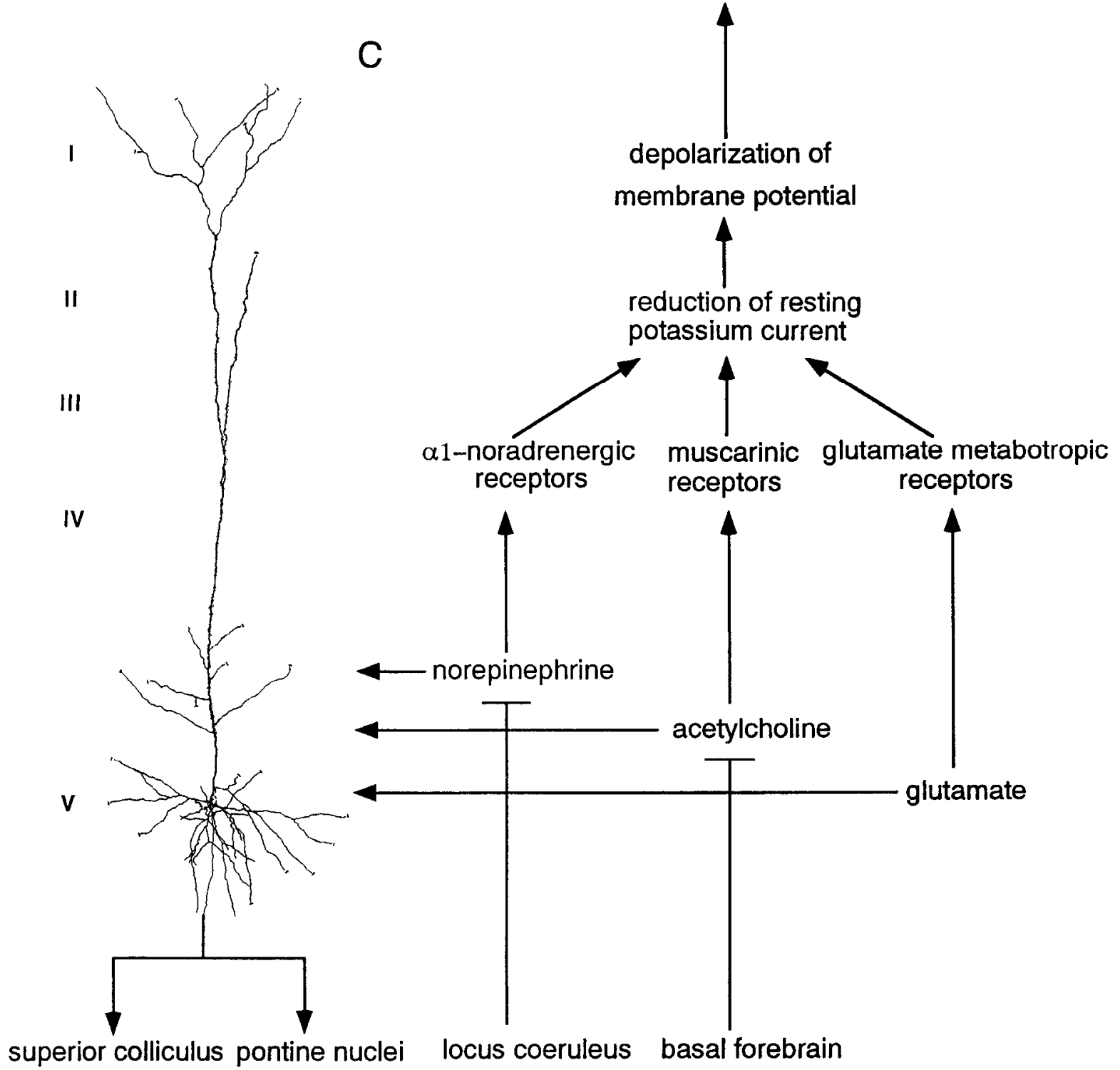

Figure 11. The summary diagram of the physiology, morphology, and pharmacology of corticotectal and corticopontine layer V burst-generating neurons. $A$, Typical firing pattern of spontaneous bursting activity at resting membrane potential and the switch in firing pattern to single-spike activity upon membrane depolarization. $B$, A typical example of the morphology of these neurons in coronal section across the layers, showing the ascending apical dendrite extending into tufts within layer $\mathrm{I}$, and sometimes bifurcating in supragranular layers. $C$, NE released from the noradrenergic terminals of LC, ACh from cholinergic fibers of basal forebrain, and possibly glutamate, depolarize these neurons by activating their corresponding receptors that lead to the reduction of resting potassium conductance and therefore switch the firing mode of these neurons. 
and consistent changes in overall pattern of activity and neuronal responsiveness to sensory and synaptic inputs during changes in arousal and the sleep-wake cycle resulting from the actions of modulatory neurotransmitters (reviewed in Steriade and McCarley, 1990; Steriade, 1991; McCormick, 1992). For example, extracellular recordings from cortical neurons, including layer $\mathrm{V}$ pyramidal cells, in vivo while animals are either drowsy or in slow-wave sleep have demonstrated the presence of spontaneous bursts of action potentials in these cells, although it is not known whether or not these represent intrinsic properties of the recorded cells or are representative of synaptic activation of these neurons from, for example, bursting thalamic cells (Hubel, 1959; Evarts, 1960, 1962, 1964). In the transition to waking and attentiveness, this spontaneous burst firing gives way to single-spike activity characterized by more broadly based interspike interval histograms, presumably resulting from a mixture of EPSPs and IPSPs, as stated by Evarts (1962): "It seems not unlikely ... that during sleep, units tend to discharge at some preferred mean rate which is in part a function of local membrane characteristics, whereas during waking an increasc in excitatory or inhibitory influences, or both, tend to cause divergence of discharge rates from this preferred frequency."

Extracellular recordings of identified corticotectal cells in the cat and rodent visual cortex reveal that these cells typically exhibit, in awake, behaving animals, a higher spontaneous firing rate than other cortical cells including corticothalamic neurons, and undergo, in general, an increase in excitability in association with arousal (Swadlow and Weyland, 1987; reviewed in Swadlow, 1983). Similarly, autoradiographic analysis of glucose uptake with ${ }^{3} \mathrm{H}$-2-deoxyglucose has demonstrated a marked decrease in activity in layers $\mathrm{V}$ and VI of the cat primary visual cortex during sleep in comparison with waking (Livingstone and Hubel, 1981). Extracellular recordings from LC neurons during sleep-wake cycles reveal that the firing rate of these cells is low during slow-wave sleep, higher during waking, and highest during arousal and attention to extrapersonal stimuli (Aston-Joncs and Bloom, 1981). Analysis of the extracellular concentrations of ACh in the cerebral cortex also reveals a marked increase in release of this neurotransmitter in the waking versus slow-wave sleep state (Szerb, 1967; Phillis, 1968), as well as during visual stimulation in anesthetized animals (Collier and Mitchell, 1966). Together with the present results, these findings suggest that increased activity in ascending noradrenergic and cholinergic pathways during periods of increased attentiveness and arousal may increase the descending output of the cerebral cortex through depolarization of layer $\mathrm{V}$ pyramidal cells. Not only will this depolarization increase the responsiveness of layer $\mathrm{V}$ cells to fast synaptic inputs, but it may also contribute to the block of slow synchronous oscillatory activity through the suppression of rhythmic burst discharges.

The ability of activation of glutamate metabotropic receptors to also change the firing mode and increase the responsiveness of layer $\mathrm{V}$ pyramidal cells suggests that these cells may be influenced in a similar manner through increased activity in glutamatergic systems. The source of various glutamatergic inputs to corticotectal or corticopontine cells and the possible activation of glutamate metabotropic receptors by one or more of these are not yet known. Electrophysiological and immunocytochemical investigations suggest that a substantial portion of corticotectal and corticopontine layer $\mathrm{V}$ pyramidal cells may release either glutamate or aspartate (Matute and Streit, 1985; Huettner and Baughman, 1988; Dinopoulos et al., 1989). Since these cells give rise to axon collaterals within layer $\mathrm{V}$ to other layer V pyramidal neurons (Gilbert and Wiesel, 1979; Gabbott et al., 1987; Chagnac-Amitai et al., 1990), they form one possible source of glutamatergic input to bursting cells. Additional sources include associational fibers from ipsi- and contralateral cortical regions and from layer II-III cells within the same cortical region. We propose that release of an excitatory amino acid from one or more of these inputs may modulate the firing mode of layer $\mathrm{V}$ burst-generating neurons through the activation of glutamate metabotropic receptors. In this manner, the level of cellular "activation" of layer V cells may not be entirely dependent upon the ascending modulatory transmitter systems such as those releasing $\mathrm{ACh}$ or $\mathrm{NE}$, but rather may also depend upon the level of activity of intracortical and corticocortical circuits. Together with our recent demonstration of the slow depolarization of thalamic relay cells via corticothalamic axons through the glutamate metabotropic receptor (McCormick and von Krosigk, 1992), these results suggest that the general level of activity in corticothalamic and intracortical circuits may contribute substantially to the cellular events that are associated with the changes in pattern of activity seen in these circuits during sleep-wake cycles and arousal and may prepare cortical and subcortical circuits for enhanced sensory processing and cognition.

\section{References}

Armstrong-James M, Fox K (1983) Effects of ionophoresed noradrenaline on the spontaneous activity of neurones in rat primary somatosensory cortex. J Physiol (Lond) 335:427-447.

Aston-Jones G, Bloom FE (1981) Activity of norepinephrine-containing locus coeruleus neurons in behaving rats anticipates fluctuations in the sleep-waking cycle. J Neurosci 1:876-886.

Ball GJ, Gloor P, Schaul N (1977) The cortical electromicrophysiology of pathological delta waves in the electroencephalogram of cats. Electroencephalogr Clin Neurophysiol 43:346-361.

Berridge CW, Foote SL (1991) Effects of locus coeruleus activation on electroencephalographic activity in neocortex and hippocampus. J Neurosci 11:3135-3145.

Bevan P, Bradshaw CM, Szabadi E (1977) The pharmacology of adrencrgic ncuronal responscs in the ccrebral cortex: evidence for excitatory $\alpha$ - and inhibitory $\beta$-receptors. Br J Pharmacol 59:635-641.

Binah O, Mager S, Palti Y (1988) Effect of $\mathrm{Cs}^{+}, \mathrm{Li}^{+}$and $\mathrm{Na}^{+}$on the potassium conductance and gating kinetics in the frog node of Ranvier. Pfluegers Arch 411:312-315.

Buzsáki G, Bickford RG, Ponomareff G, Thal LJ, Mandel R, Gage FH (1988) Nucleus basalis and thalamic control of neocortical activity in the freely moving rat. J Neurosci 8:4007-4026.

Calvet J, Fourment A, Thieffry M (1973) Electrical activity in neocortical projection and association areas during slow wave sleep. Brain Res 52:173-187.

Chagnac-Amitai Y, Connors BW (1989) Synchronized excitation and inhibition driven by intrinsically bursting neurons in neocortex. $J$ Neurophysiol 62:1149-1162.

Chagnac-Amitai Y, Luhmann HJ, Prince DA (1990) Burst generating and regular spiking layer 5 pyramidal neurons of rat neocortex have different morphological features. J Comp Neurol 296:598-613.

Charpak S, Gähwiler BH, Do KQ, Knöpfel T (1990) Potassium conductances in hippocampal neurons blocked by excitatory amino-acid transmitters. Nature 347:765-767.

Collier B, Mitchell JF (1966) The central release of acetylcholine during stimulation of the visual pathway. J Physiol (Lond) 184:239-254

Connors BW (1984) Initiation of synchronized neuronal bursting in neocortex. Nature 310:685-687.

Connors BW, Gutnick MJ (1990) Intrinsic firing patterns of diverse neocortical neurons. Trends Neurosci 13:99-104.

Connors BW, Gutnick MJ, Prince DA (1982) Electrophysiological properties of neocortical neurons in vitro. J Neurophysiol 48:13021320.

Cortés R, Palacios JM (1986) Muscarinic cholinergic receptor subtypes 
in the rat brain. I. Quantitative autoradiographic studies. Brain Res $362: 227-238$.

Creutzfeldt O, Watanabe S, Lux HD (1966) Relations between EEG phenomena and potentials of single cells. I. Evoked responses after thalamic and epicortical stimulation. Electroencephalogr Clin Neurophysiol 20:1-18.

Dinopoulos A, Dori I, Davies SW, Paravelas JG (1989) Neurochemical heterogeneity among corticofugal and callosal projections. Exp Neurol 105:36-44.

Eckenstein FP, Baughman RW, Quinn J (1988) An anatomical study of cholinergic innervation in rat cerebral cortex. Neuroscience 25: $457-474$.

Evarts EV (1960) Effects of slecp and waking on spontaneous and evoked discharge of single units in visual cortex. Fed Proc 19[Suppl 4]:828-837.

Evarts EV (1962) Spontaneous discharge of single neurons during sleep and waking. Science 135:726-728.

Evarts EV (1964) Temporal patterns of discharge of pyramidal tract neurons during sleep and waking in the monkey. $\mathrm{J}$ Neurophysiol 27: 152-171.

Foehring RC, Lorenzon NM, Herron P, Wilson CJ (1991) Correlation of physiologically and morphologically identified neuronal types in human association cortex in vitro. J Neurophysiol 66:1825-1837.

Foote SL, Morrison JH (1987) Extrathalamic modulation of cortical function. Annu Rev Neurosci 10:67-95.

Gabbott PLA, Martin KAC, Whiteridge D (1987) Connections between pyramidal neurons in layer 5 of cat visual cortex (area 17). J Comp Neurol 259:364-381.

Gilbert CD, Kelly JP (1975) The projections of cells in different layers of the cat's visual cortex. J Comp Neurol 163:81-106.

Gilbert CD, Wiesel TN (1979) Morphology and intracortical projections of functionally characterised neurones in the cat visual cortcx. Nature 280:120-125.

Halliwell JV, Adams PR (1982) Voltage-clamp analysis of muscarinic excitation in hippocampal neurons. Brain Res 250:71-92.

Hallman LE, Schofield BR, Lin CS (1988) Dendritic morphology and axon collaterals of corticotectal, corticopontine and callosal neurons in layer V of primary visual cortex of the hooded rat. J Comp Neurol $272: 149-160$

Houser CR, Crawford GD, Salvaterra PM, Vaughn JE (1985) Immunocytochemical localization of choline acetyltransferase in rat cerebral cortex: a study of cholinergic neurons and synapses. J Comp Neurol 234:17-34.

Hubel DH (1959) Single unit activity in striate cortex of unrestrained cats. J Physiol (Lond) 147:226-238

Hüberner M, Schwarz C, Bolz J (1990) Morphological types of projection neurons in layer 5 of cat visual cortex. J Comp Neurol 301: 655-674.

Huettner JE, Baughman RW (1988) The pharmacology of synapses formed by identified corticocollicular neurons in primary cultures of rat visual cortex. J Neurosci 8:160-175.

Jones BE, Harper ST, Halaris AE (1977) Effects of locus coeruleus lesions upon cerebral monoamine content, sleep-wakefulness states and the response to amphetamine in the cat. Brain Res 124:473-496.

Jones LS, Gauger LL, Davis JN (1985) Anatomy of brain alpha.adrenergic receptors: in vitro autoradiography with [125] ${ }^{125}$-HEAT. J Comp Neurol 231:190-208.

Kasper E, Larkman A, Blakemore C, Judge S (1991) Physiology and morphology of identified projection neurons in rat visual cortex studied in vitro. Soc Neurosci Abstr 17:114.

Katz LC, Iarovici DM (1990) Green fluorescent latex microspheres: a new retrograde tracer. Neuroscience 34:511-520.

Katz LC, Burkhalter A, Dreyer WJ (1984) Fluorescent latex microspheres as a retrograde neuronal marker for in vivo and in vitro studies of visual cortex. Nature 310:499-500.

Krnjevic K (1975) Chemical nature of synaptic transmission in vertebrates. Physiol Rev 54:418-540.

Larkman A, Mason A (1990) Correlations between morphology and electrophysiology of pyramidal neurons in slices of rat visual cortex. I. Establishment of cell classes. J Neurosci 10:1407-1414.

Livingstone MS, Hubel DH (1981) Effects of sleep and arousal on the processing of visual information in the cat. Nature 291:554-561.

Lysakowski A, Wainer BH, Bruce G, Hersh LB (1989) An atlas of the regional and laminar distribution of choline acetyltransferase immunoreactivity in rat cerebral cortex. Neuroscience 28:291-336.
Madison DV, Nicoll RA (1986) Actions of noradrenaline recorded intracellularly in rat hippocampal CAl pyramidal neurones, in vitro. J Physiol (Lond) 372:221-244.

Madison DV, Lancaster B, Nicoll RA (1987) Voltage clamp analysis of cholinergic action in the hippocampus. J Neurosci 7:733-741.

Mash DC, Potter LT (1986) Autoradiographic localization of $\mathbf{M}_{4}$ and $M$, muscarinic receptors in rat brain. Neuroscience 19:551-564.

Mason A, Larkman A (1990) Correlations between morphology and electrophysiology of pyramidal neurons in slices of rat visual cortex. II. Electrophysiology. J Neurosci 10:1415-1428.

Matute C, Streit P (1985) Selective retrograde labeling with $\mathrm{D}-\left[{ }^{3} \mathrm{H}\right]-$ aspartate in afferents to the mammalian superior colliculus. J Comp Ncurol 241:34-49.

McCormick DA (1991) Cellular mechanisms underlying cholinergic and noradrenergic modulation of neuronal firing mode in the cat and guinea pig dorsal lateral geniculate nucleus. J Neurosci 12:278-289.

McCormick DA (1992) Neurotransmitter actions in the thalamus and cerebral cortex and their role in neuromodulation of thalamocortical activity. Prog Neurobiol 39:337-388.

McCormick DA, Prince DA (1986) Mechanisms of action of acetylcholine in the guinea-pig cerebral cortex in vitro. J Physiol (Lond) 375:169-194.

McCormick DA, von Krosigk M (1992) Corticothalamic activation modulates thalamic firing through glutamate "metabotropic" receptors. Proc Natl Acad Sci USA 89:2774-2778.

McCormick DA, Williamson A (1989) Convergence and divergence of neurotransmitter action in human cerebral cortex. Proc Natl Acad Sci USA 86:8098-8102.

McCormick DA, Connors BW, Lighthall JW, Prince DA (1985) Comparative electrophysiology of pyramidal and sparsely spiny stellate neurons of the neocortex. J Neurophysiol 54:782-806.

Montoro RJ, López-Barneo J, Jassik-Gerschenfeld D (1988) Differential burst firing modes in neurons of the mammalian visual cortex in vitro. Brain Res 460:168-172.

Morrison JH, Magistretti PJ (1983) Monoamines and peptides in cerebral cortex. Contrasting principles of cortical organization. Trends Neurosci 6:146-151.

Parnavelas JG, Papadopoulos GC (1989) The monoaminergic innervation of the cerebral cortex is not diffuse and nonspecific. Trends Neurosci 12:315-319.

Phillis JW (1968) Acetylcholine release from the cerebral cortex: its role in cortical arousal. Brain Res 7:378-389.

Rappelsberger P, Pockberger H, Petsche H (1982) The contribution of the cortical layers to the generation of the EEG: field potential and current source density analyses in the rabbit's visual cortex. Electrocnccphalogr Clin Ncurophysiol 53:254-269.

Schofield BR, Hallman LE, Lin CS (1987) Morphology of corticotectal cells in the primary visual cortex of hooded rats. J Comp Neurol 261 : 85-97.

Schwindt PC, Spain WJ, Foehring RC, Chubb MC, Crill WE (1988) Slow conductances in neurons from cat sensorimotor cortex in vitro and their role in slow excitability changes. J Neurophysiol 59:450 467

Silva LS, Amitai Y, Connors BW (1991) Intrinsic oscillations of neocortex generated by layer 5 pyramidal neurons. Science 251:432-435.

Steriade M (1991) Alertness, quiet sleep, dreaming. In: Cerebral cortex, Vol 9 (Peters A, ed), pp 279-357. New York: Plenum.

Steriade M, McCarley RW (1990) Brainstem control of wakefulness and sleep. New York: Plenum.

Sutor B, Zieglgansberger W (1987) A low-voltage activated, transient calcium current is responsible for the time-dependent depolarizing inward rectification of rat neocortical neurons in vitro. Pfluegers Arch 410:102-111.

Swadlow HA (1983) Efferent systems of primary visual cortex: a review of structure and function. Brain Res Rev 6:1-24.

Swadlow HA, Weyand TG (1987) Corticogeniculate neurons, corticotectal neurons, and suspected interneurons in visual cortex of awake rabbits: receptive-field properties, axonal properties, and effects of EEG arousal. J Neurophysiol 57:977-1001.

Szerb JC (1967) Cortical acetylcholine release and electroencephalographic arousal. J Physiol (Lond) 192:329-343.

Tseng GF, Parada I, Prince DA (1991) Double-labelling with rhodamine beads and biocytin: a technique for studying corticospinal and other projection neurons in vitro. J Neurosci Methods 37:121131. 
van Brederode JFM, Snyder GL (1992) A comparison of the electrophysiological properties of morphologically identified cells in layers 5B and 6 of the rat neocortex. Neuroscience 50:315-337.

Vanderwolf $\mathrm{CH}$ (1988) Cerebral activity and behavior: control by central cholinergic and serotoninergic systems. Int Rev Neurobiol 30: 225-340.

Wang Z, McCormick DA (1991) Activation of glutamate metabotropic, muscarinic, and $\alpha_{1}$-receptors controls firing mode in neocortical bursting neurons. Soc Neurosci Abstr 17:254.

Wang Z, McCormick DA (1992) Functional properties of burst and single spike firing in layer $\mathrm{V}$ cortical burst generating neurons. Soc Neurosci Abstr 18:217.
Waterhouse BD, Moises HC, Woodward DJ (1981) Alpha-receptormediated facilitation of somatosensory cortical neuronal responses to excitatory synaptic inputs and iontophoretically applied acetylcholine. Neuropharmacology 20:907-920.

Wise SP, Jones EG (1977) Cells of origin and terminal distribution of descending projections of the rat somatic sensory cortex. J Comp Neurol 175:129-158.

Wong RKS, Traub RD (1983) Synchronized burst discharge in disinhibited slice. I. Initiation in CA2-CA3 region. J Neurophysiol 49: $442-458$. 